\title{
Transient Oxygen/Glucose Deprivation Causes a Delayed Loss of Mitochondria and Increases Spontaneous Calcium Signaling in Astrocytic Processes
}

\author{
John C. 0'Donnell, ${ }^{1,3}{ }^{-}$Joshua G. Jackson, ${ }^{1}$ and ${ }^{\circledR}$ Michael B. Robinson ${ }^{1,2,3}$ \\ ${ }^{1}$ Children's Hospital of Philadelphia Research Institute, ${ }^{2}$ Department of Pediatrics, and ${ }^{3}$ Department of Systems Pharmacology and Translational \\ Therapeutics, University of Pennsylvania, Philadelphia, Pennsylvania 19104
}

Recently, mitochondria have been localized to astrocytic processes where they shape $\mathrm{Ca}^{2+}$ signaling; this relationship has not been examined in models of ischemia/reperfusion. We biolistically transfected astrocytes in rat hippocampal slice cultures to facilitate fluorescent confocal microscopy, and subjected these slices to transient oxygen/glucose deprivation (OGD) that causes delayed excitotoxic death of CA1 pyramidal neurons. This insult caused a delayed loss of mitochondria from astrocytic processes and increased colocalization of mitochondria with the autophagosome marker LC3B. The losses of neurons in area CA1 and mitochondria in astrocytic processes were blocked by ionotropic glutamate receptor (iGluR) antagonists, tetrodotoxin, ziconotide ( $\mathrm{Ca}^{2+}$ channel blocker), two inhibitors of reversed $\mathrm{Na}^{+} / \mathrm{Ca}^{2+}$ exchange (KB-R7943, YM-244769), or two inhibitors of calcineurin (cyclosporin-A, FK506). The effects of OGD were mimicked by NMDA. The glutamate uptake inhibitor (3S)-3-[[3-[[4-(trifluoromethyl)benzoyl]amino]phenyl]methoxy]-L-aspartate increased neuronal loss after OGD or NMDA, and blocked the loss of astrocytic mitochondria. Exogenous glutamate in the presence of iGluR antagonists caused a loss of mitochondria without a decrease in neurons in area CA1. Using the genetic $\mathrm{Ca}^{2+}$ indicator Lck-GCaMP-6S, we observed two types of $\mathrm{Ca}^{2+}$ signals: (1) in the cytoplasm surrounding mitochondria (mitochondrially centered) and (2) traversing the space between mitochondria (extramitochondrial). The spatial spread, kinetics, and frequency of these events were different. The amplitude of both types was doubled and the spread of both types changed by $\sim 2$-fold $24 \mathrm{~h}$ after OGD. Together, these data suggest that pathologic activation of glutamate transport and increased astrocytic $\mathrm{Ca}^{2+}$ through reversed $\mathrm{Na}^{+} / \mathrm{Ca}^{2+}$ exchange triggers mitochondrial loss and dramatic increases in $\mathrm{Ca}^{2+}$ signaling in astrocytic processes.

Key words: astrocytes; calcium; glutamate transport; mitochondria; mitophagy; oxygen/glucose deprivation

Significance Statement

Astrocytes, the most abundant cell type in the brain, are vital integrators of signaling and metabolism. Each astrocyte consists of many long, thin branches, called processes, which ensheathe vasculature and thousands of synapses. Mitochondria occupy the majority of each process. This occupancy is decreased by $\sim 50 \% 24 \mathrm{~h}$ after an in vitro model of ischemia/reperfusion injury, due to delayed fragmentation and mitophagy. The mechanism appears to be independent of neuropathology, instead involving an extended period of high glutamate uptake into astrocytes. Our data suggest that mitochondria serve as spatial buffers, and possibly even as a source of calcium signals in astrocytic processes. Loss of mitochondria resulted in drastically altered calcium signaling that could disrupt neurovascular coupling and gliotransmission.

\section{Introduction}

Recent studies have shown that mitochondria are found throughout the fine processes of astrocytes (Lovatt et al., 2007; Genda et al., 2011; Lavialle et al., 2011; Jackson et al., 2014; Derouiche et al., 2015; Jackson and Robinson, 2015; Stephen et al., 2015; for review, see Robinson and Jackson, 2016). As is observed in neurons and other cells, positioning of mitochondria reflects local energy demands and ion buffering (for review, see Frederick and Shaw, 2007; Sheng and Cai, 2012; Schwarz, 2013). Neuronal activity and $\mathrm{Ca}^{2+}$ influx immobilize mitochondria in astrocytic

GM008076) followed by an individual National Research Service Award (F31 NS086255). We are grateful for the imaging support of Drs. Douglas Coulter and Hajime Takano (Cellular Neuroscience Core) and statistical support from Dr. Mary Putt (Biostatistics and Bioinformatics Core) of the Institutional Intellectual and Developmental Disabilities Research Center (U54 HD086984). We also thank members of the Robinson laboratory for their advice and suggestions during the conduct of this research. 
processes near clusters of the glutamate transporter GLT-1 that appose synapses (Jackson et al., 2014; Stephen et al., 2015). Immobilization is facilitated by $\mathrm{Ca}^{2+}$ binding to motor adaptor proteins (Miro1 and Miro2), and mitochondria shape $\mathrm{Ca}^{2+}$ signals in astrocytic processes (Jackson and Robinson, 2015; Stephen et al., 2015).

Cerebral ischemia/reperfusion (I/R) injury, as occurs with traumatic brain injury, cardiac arrest, or stroke, is followed by a delayed period of secondary pathology that is self-propagating and progressive. It involves excitotoxic and inflammatory mechanisms and can last for weeks after the initial insult (for review, see Choi and Rothman, 1990; Lipton, 1999; Borgens and LiuSnyder, 2012). This secondary pathology is currently untreatable. Although neuron-targeted approaches [e.g., blocking ionotropic glutamate receptors (iGluRs) or their downstream effectors] attenuated damage in preclinical models of I/R injury, they failed in clinical trials (Liebeskind and Kasner, 2001; Muir, 2006). Astrocytes are much more resilient to this type of injury and may play an important role in the damage observed (for review, see Chen and Swanson, 2003; Rossi et al., 2007; Barreto et al., 2011). In fact, targeting the SNARE pathway, stimulating purinergic receptors, or manipulating microRNAs in astrocytes all reduce damage in models of stroke (Hines and Haydon, 2013; Zheng et al., 2013; Ouyang et al., 2014).

Although astrocytic mitochondria have been studied in the context of I/R injury, previous work focused mainly on the reticular mitochondria found in cell bodies of dissociated astrocytic cultures (Bambrick et al., 2004; Dugan and Kim-Han, 2004; Ouyang et al., 2011, 2012). Few studies have focused on mitochondria in the fine astrocytic processes or their role in disease. One such study using electron microscopy in cortical sections after middle cerebral artery occlusion in gerbils reported signs of degenerated astrocytic processes and mitochondria near the infarct, correlating with the progression of neuropathology (Ito et al., 2009). More recently, a study using cortical stab wounds in mice revealed transient, inflammation-induced fragmentation of mitochondria in the processes of astrocytes adjacent to the injury site. Recovery of mitochondrial fission/fusion balance required mitophagy (Motori et al., 2013).

Here we present the first evidence that transient oxygen/glucose deprivation (OGD) results in delayed fragmentation and autophagic degradation of mitochondria in astrocytic processes. These effects are blocked by iGluR antagonists; by inhibitors of action potential propagation, vesicular neurotransmitter release, glutamate transport, or reversal of $\mathrm{Na}^{+} / \mathrm{Ca}^{2+}$ exchangers (NCXs); and by two different molecules that prevent $\mathrm{Ca}^{2+}$ induced mitochondrial depolarization in astrocytes. The effects of OGD are mimicked by NMDA. The effects on astrocytic mitochondria are also mimicked by exogenous glutamate in the presence of iGluR antagonists that block any glutamate-induced loss of CA1 neurons. We also demonstrate that spontaneous cytosolic $\mathrm{Ca}^{2+}$ signaling is dramatically increased $24 \mathrm{~h}$ after this transient insult. This loss of mitochondria and increase in $\mathrm{Ca}^{2+}$ signaling likely alters various astrocytic functions, including glutamate metabolism, gliotransmitter release, and neurovascular coupling, all of which are important during recovery after I/R.

The authors declare no competing financial interests.

Correspondence should be addressed to Michael B. Robinson, Department of Pediatrics, 502N, Abramson Pediatric Research Building, 3615 Civic Center Boulevard, Philadelphia, PA 19104-3779. E-mail: Robinson@mail.med.upenn.edu.

DOI:10.1523/JNEUROSCI.4518-15.2016

Copyright $\odot 2016$ the authors $\quad 0270-6474 / 16 / 367110-19 \$ 15.00 / 0$

\section{Materials and Methods}

cDNA constructs. We used Mito-EGFP, gfap-gap43-mcherry, gfapDsRed2-mito, and Lck-GCaMP-6S, which have been described previously (Jackson et al., 2014; Jackson and Robinson, 2015). Mito-EGFP (also called pEGFP-mito; a gift from Dr. Stanley Thayer, University of Minnesota, Minneapolis) is a fusion of the mitochondrial matrix targeting sequence from CoxVIII with EGFP, and has been shown to result in specific targeting of EGFP into mitochondria (Rizzuto et al., 1993; Wang et al., 2003). gfap-gap43-mcherry (also called pTY-Gfa $\mathrm{ABC1D}^{-}$ gap $43 \mathrm{mCherry)}$ was generated by inserting the membrane-targeting palmitoylation sequence of gap43 into pTYGfa $\mathrm{ABC1D}_{\mathrm{D}}$-mCherry (a gift from Dr. John Wolfe, University of Pennsylvania). gfap-DsRed2-mito (also called $\mathrm{pGFA}_{\mathrm{ABC1D}}$ :DsRed2mito) was generated by replacing the CMV promoter of pDsRed2-mito (Clontech, catalog \#632421) with the minimal GFAP promoter $\left(\mathrm{GFA}_{\mathrm{ABC1}}\right)$ from gfap-gap43-mcherry. LckGCaMP-6S was generated by transferring the Lck-derived membranetethering domain from Lck-GCaMP-5G (a gift from Baljit Khakh; Addgene plasmid \#34924; Akerboom et al., 2012) in-frame with GCaMP-6s (a gift from Douglas Kim; Addgene plasmid \#40753; Chen et al., 2013). EGFP-LC3B (also called pEGFP-LC3; human) was obtained from Addgene (plasmid \#24920) and was originally a gift from Toren Finkel (Lee et al., 2008).

Reagents. Bafilomycin A1 (BfA) from Streptomyces griseus (catalog \#B1793), FK-506 monohydrate (catalog \#F4679), ziconotide ( $\omega$-conotoxin MVIIA; catalog \#C1182), and L-glutamic acid (catalog \#G1251) were purchased from Sigma-Aldrich. Tetrodotoxin (TTX) was purchased from Alomone Labs (catalog \#T-550). Cyclosporin A (CsA; catalog \#1101), (5S,10R)-(+)-5-methyl-10,11-dihydro-5H-dibenzo[a,d]cyclohepten-5,10imine maleate (MK801; catalog \#0924), 2,3-dioxo-6-nitro-1,2,3,4-tetrahydrobenzo[f] quinoxaline-7-sulfonamide disodium salt (NBQX; catalog \#1044), NMDA (catalog \#0114), (3S)-3-[[3-[[4-(trifluoromethyl)benzoyl]amino]phenyl]methoxy]-L-aspartic acid (TFB-TBOA; catalog \#2532), 2-[2-[4-(4-nitrobenzyloxy)phenyl] ethyl] isothiourea mesylate (KBR7943; catalog \#1244), and N-[(3-aminophenyl)methyl]-6-[4-[(3-fluorophenyl)methoxy]phenoxy]-3-pyridinecarboxamide dihydrochloride (YM-244769; catalog \#4544) were purchased from Tocris Bioscience.

Hippocampal slice cultures and biolistic transfection. Organotypic hippocampal slices were cultured based on the method of Stoppini et al. (1991), as previously described (Genda et al., 2011; Jackson et al., 2014). Following decapitation of rat pups [postnatal day (P) 6-P8] of either sex, brains were removed and immediately placed in ice-cold sucrosesupplemented artificial CSF (ACSF) containing the following (in $\mathrm{mm}$ ): 280 sucrose, $5 \mathrm{KCl}, 2 \mathrm{MgCl}_{2}, 1 \mathrm{CaCl}_{2}, 20$ glucose, and 10 HEPES, pH 7.3. Hippocampi were dissected on ice and cut into coronal sections $300 \mu \mathrm{m}$ thick using a McIlwain tissue chopper. Slices were then transferred onto Millicell membrane inserts (EMD Millipore, catalog \#PICM0RG50) in six-well plates atop $1 \mathrm{ml}$ of media consisting of $50 \%$ Neurobasal medium (containing $25 \mathrm{~mm}$ glucose and $10 \mathrm{~mm}$ HEPES; Invitrogen, catalog \#21103-049), 25\% horse serum, 25\% HBSS, supplemented with $10 \mathrm{~mm}$ HEPES, $36 \mathrm{~mm}$ glucose, $2 \mathrm{~mm}$ glutamine, $10 \mathrm{U} / \mathrm{ml}$ penicillin, $100 \mu \mathrm{g} / \mathrm{ml}$ streptomycin, and Gem21 Neuroplex (1:50 dilution from 50× stock; Gemini, catalog \#400-160), pH 7.3. Slice cultures were maintained in an incubator at $37^{\circ} \mathrm{C}$ with $5 \% \mathrm{CO}_{2}$.

At 2 DIV, slices were fed $(350 \mu \mathrm{l}$ of media was replaced with $350 \mu \mathrm{l}$ of fresh media), and biolistically transfected with cDNAs encoding fluorophores relevant to each experiment. Biolistic transfection was performed as described previously (Genda et al., 2011; Jackson et al., 2014) using the Helios Gene Gun System (Bio-Rad, catalog \#1652431; a generous gift from Dr. Rita Balice-Gordon), in which compressed helium fires cDNAcoated gold particles into slices, resulting in a sparse transfection pattern ideal for imaging individual cells in a slice culture. Using 1- $\mu \mathrm{m}$-diameter gold particles results in preferential transfection of astrocytes (Benediktsson et al., 2005; Genda et al., 2011), and additional astrocyte selectivity was achieved by including one construct driven by a minimal GFAP promoter in each experiment (de Leeuw et al., 2006). At 4 DIV, inserts were transferred to $1 \mathrm{ml}$ of "serum-free" media consisting of Neurobasal-A medium (containing 25 mm glucose and 10 mM HEPES; Invitrogen, catalog \#10888-022) supplemented with 2 mM GlutaMAX 


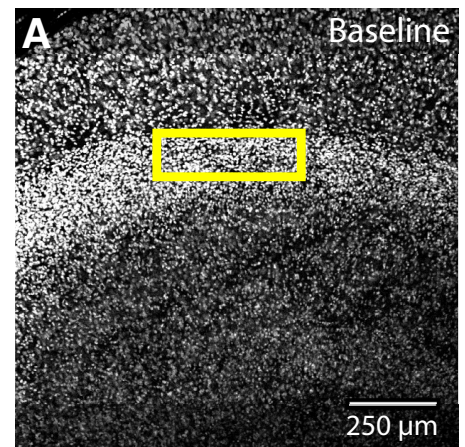

Stratum Pyramidale

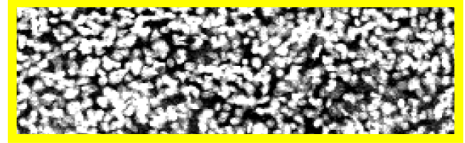

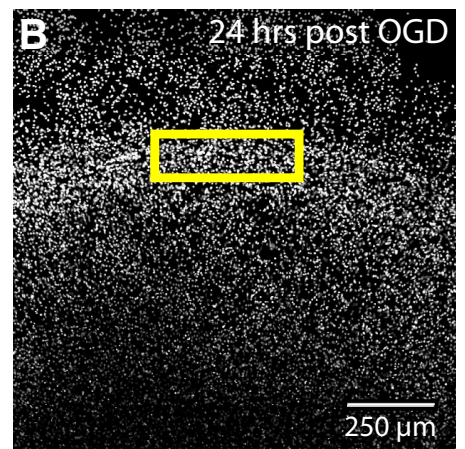

Stratum Pyramidale

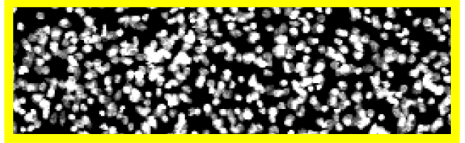

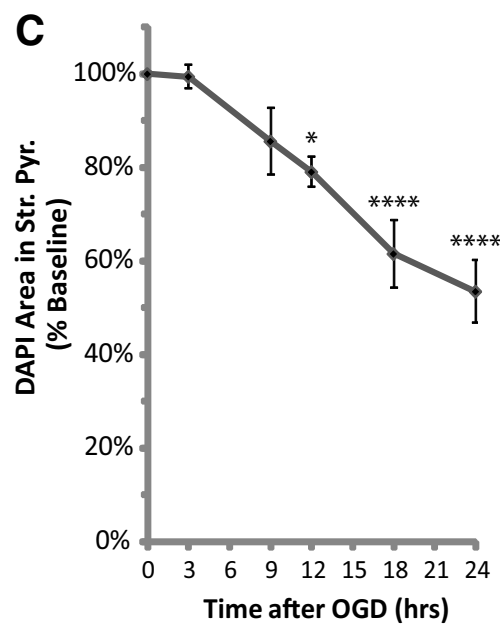

Figure 1. Thirty minutes of OGD caused a delayed loss of cells from stratum pyramidale, the neuronal cell-body layer of area CA1. Hippocampal slice cultures with astrocytes expressing mitochondrially targeted EGFP and plasma-membrane-targeted mcherry were fixed in 4\% paraformaldehyde before, as well as 3,9, 12, 18, and $24 \mathrm{~h}$ after a 30 min $0 G D$ injury, and stained with DAPI in mounting medium. $A, B$, Representative images of DAPI staining in area CA1 at baseline and $24 \mathrm{~h}$ after $0 G \mathrm{G}$, with insets providing magnified views of the neuronal cell-body layer, stratum pyramidale. $C$, Mean DAPI area in stratum pyramidale expressed as a percentage of baseline values from each individual experiment. All groups were included in $\geq 3$ experiments, with slice cultures prepared from $\geq 3$ separate animals. $n=6-12$ slices/group ( $2-4$ slices/group/experiment, 2 astrocytes/slice). Error bars indicate SEM. ${ }^{*} p<0.05$, ${ }^{* * * *} p<0.0001$ compared with baseline by one-way ANOVA with Bonferroni's correction for multiple comparisons. Mean values for Baseline (no insult/no incubation) and a $24 \mathrm{~h}$ Control group (no insult/24 h incubation) were not different (data not shown).

(Invitrogen, catalog \#35050-061), $10 \mathrm{U} / \mathrm{ml}$ penicillin, $100 \mu \mathrm{g} / \mathrm{ml}$ streptomycin, and Gem21 Neuroplex, $\mathrm{pH}$ 7.3. Slice cultures were maintained in an incubator at $37^{\circ} \mathrm{C}$ with $5 \% \mathrm{CO}_{2}$, and fed every other day $(350 \mu \mathrm{l}$ of media replaced). Experiments were performed at 14-18 DIV, when synapse formation and NMDAR subunit expression have reached a developmental stage sufficient to sensitize the slice to excitotoxic injury (Ahlgren et al., 2011), and several weeks before the emergence of spontaneous epileptiform activity (Albus et al., 2013).

OGD injury. Two to $4 \mathrm{~d}$ before each experiment, slice cultures were screened on a Nikon Eclipse TS100 microscope by bright-field transmission for vitality (Trumbeckaite et al., 2013) and epifluorescence for transfection quality. Several criteria were used to exclude slices, including a lack of clear cell-body layers containing dentate granule cells or pyramidal cells, darkening of area CA1, discrete areas of cell loss, disconnection between layers of hippocampus, or an insufficient number of transfected astrocytes in stratum radiatum. Variable spreading of slice cultures was observed during the 14-18 DIV. Therefore cultures were randomly assigned to different groups. One day before each experiment, serumfree OGD media with no pyruvate and equimolar replacement of glucose with nonmetabolizable 2-deoxyglucose [specialty Neurobasal-A medium (no glucose, no pyruvate, $10 \mathrm{~mm}$ HEPES; Invitrogen , catalog \#A24775-01) supplemented with $25 \mathrm{~mm}$ 2-deoxyglucose, $2 \mathrm{~mm}$ GlutaMAX (Invitrogen, catalog \#35050-061), $10 \mathrm{U} / \mathrm{ml}$ penicillin, 100 $\mu \mathrm{g} / \mathrm{ml}$ streptomycin, and Gem21 Neuroplex, $\mathrm{pH} 7.3$ ] was distributed onto six-well plates ( $4 \mathrm{ml} /$ well) and placed in a modular hypoxia chamber (Billups-Rothenberg, catalog \#MIC-101). The chamber/media was pre-equilibrated with $95 \% \mathrm{~N}_{2} / 5 \% \mathrm{CO}_{2}$ at $37^{\circ} \mathrm{C}$ overnight.

On the day of the experiment, all slices were rinsed and then preequilibrated in an incubator at $37^{\circ} \mathrm{C}$ and $5 \% \mathrm{CO}_{2}$ for $30 \mathrm{~min}$ in fresh serum-free media containing glucose with and without drugs. Drug treatment concentrations were as follows: $50 \mathrm{nM}$ BfA, $10 \mu \mathrm{M}$ MK801, 20 $\mu \mathrm{M}$ NBQX, $3 \mu \mathrm{M}$ TFB-TBOA, $1 \mu \mathrm{M}$ TTX, $0.5 \mu \mathrm{M}$ ziconotide, $15 \mu \mathrm{M}$ KB-R7943, $1 \mu \mathrm{M}$ YM-244769, $10 \mu \mathrm{M}$ CsA, $10 \mu \mathrm{M}$ FK506. These slices were then rinsed in either OGD or glucose-containing media with or without $\operatorname{drug}(\mathrm{s})$. Some slices were moved back to the media used for preequilibration (controls). The remainder of the slices were submerged in OGD media $(4 \mathrm{ml})$ with or without drug and placed in the hypoxia chamber charged with $95 \% \mathrm{~N}_{2} / 5 \% \mathrm{CO}_{2}$ for 5 min at 2 psi, sealed, and placed at $37^{\circ} \mathrm{C}$ for $30 \mathrm{~min}$. Slices treated with NMDA were submerged in glucose-containing media with 10 or $100 \mu \mathrm{M}$ NMDA and returned to the culture incubator for $30 \mathrm{~min}$. Slices were submerged in glucose- containing media with iGluR antagonists $(10 \mu \mathrm{M}$ MK801 and $20 \mu \mathrm{M}$ $\mathrm{NBQX}$ ) in the presence or absence of $1 \mathrm{~mm}$ L-glutamate for different periods of time in an incubator. After the insult (OGD, NMDA, or glutamate), the slices were rinsed twice in serum-free media containing glucose with or without drugs and then returned to the media used for pre-equilibration. They were then maintained in an incubator at $37^{\circ} \mathrm{C}$ and $5 \% \mathrm{CO}_{2}$ for $\leq 24 \mathrm{~h}$. For experiments involving fixation, slices were rinsed in PBS, submerged in $4 \%$ paraformaldehyde in PBS for $10 \mathrm{~min}$, rinsed again in PBS, and then stored in PBS in the dark at $4^{\circ} \mathrm{C}$. Slices were cut out and mounted on slides with the transwell membrane against the slide and the slice against coverslip using Vectashield Antifade Mounting Medium with DAPI (Vector Laboratories, catalog \#H-1200).

Fixed imaging and analyses. All images were acquired using an Olympus Fluoview 1000 laser scanning confocal microscope equipped with $10 \times$ and $40 \times$ UPlanApo objectives (numerical aperture 0.4 and 1.3, respectively). All images were processed and analyzed using freely available FIJI/ImageJ software (Schindelin et al., 2012).

DAPI image stacks were acquired from area CA1 using the $10 \times$ objective and $405 \mathrm{~nm}$ laser for the entire thickness of the stained slice with a $5 \mu \mathrm{m}$ step size and $512 \times 512$ pixels/section. Image processing consisted of automated background subtraction (rolling ball algorithm, 50 pixel radius), maximum $z$-projection, and conversion to binary masks. After processing, images were copied and assigned randomized numeric file names for blinded analysis. DAPI area in the neuronal cell-body layer of CA1, stratum pyramidale, was quantified using a standardized rectangular region of interest (ROI), displayed in Figure $1 A, B$. All groups were included in $\geq 3$ experiments, with slice cultures prepared from $\geq 3$ separate animals. Each slice was considered an $n$ of 1 (2-4 slices/ group/experiment).

Images of mitochondrially targeted EGFP (mito-EGFP) and minimalGFAP-promoter-driven, plasma-membrane-targeted mcherry (gfapgap43-mcherry) were acquired from stratum radiatum and pyramidale in area CA1 using the $40 \times$ objective with 488 and $546 \mathrm{~nm}$ lasers, respectively. Obviously hypertrophic astrocytes were rarely observed during the $24 \mathrm{~h}$ after insult, and were therefore excluded to avoid confounding the analysis by sampling a heterogeneous population. Image stacks spanned the depth of each astrocyte with a step size of $1 \mu \mathrm{m}$, at $800 \times 800$ pixels/ section. Image processing of both channels consisted of automated background subtraction and maximum $z$-projection, and the mitochondrial channel was converted to a binary mask for cleaner quantification of length and number. After processing, images were copied and assigned 
randomized numeric file names for blinded analysis. Channels from the same image received the same randomized numeric file name along with a channel identifier. Linear ROIs were traced along three separate processes from distal tip, back through tertiary and secondary branches, and through the primary process to the edge of the soma in the plasma membrane channel (gfap-gap43-mcherry). These ROIs were then transferred to the mitochondrial channel (mito-EGFP), where they were used to measure the length of the process, the number of mitochondria, and the lengths of the mitochondria. These values were used to calculate the mean number of mitochondria, length of mitochondria, and percentage occupancy (percentage of the process occupied by mitochondria) for each astrocyte. All groups were included in $\geq 3$ experiments, with slice cultures prepared from $\geq 3$ separate animals. Each slice was considered an $n$ of 1 (2-4 slices/group/experiment, 2 astrocytes/slice, 3 processes/astrocyte).

The microtubule-associated protein LC3B is incorporated into autophagosomes during their formation, which is why LC3B is a widely used marker for these structures (Tanida et al., 2008; Maday et al., 2012). Slices were treated with BfA to inhibit lysosomal maturation and allow for detection of cumulative mitophagy in fixed slices 9 and $24 \mathrm{~h}$ after OGD (for review, see Dröse and Altendorf, 1997). Images of EGFPtagged LC3B (EGFP-LC3B) and minimal-GFAP-promoter-driven, mitochondrially targeted DsRed2 (gfap-DsRed2-mito) were acquired from area CA1 using the $40 \times$ objective with 488 and $546 \mathrm{~nm}$ lasers, respectively. Hypertrophic reactive astrocytes were avoided. Image stacks spanned the depth of each astrocyte with a step size of $1 \mu \mathrm{m}$, at $800 \times 800$ pixels/section. Exogenous EGFP-LC3B expression appeared as a bimodal signal due to a diffuse, low-intensity, cytosolic fluorescence, and the higher-intensity, punctate fluorescence from autophagosomes. To filter out the diffuse cytosolic signal, FIJI's "Minimum" thresholding method was used to generate binary masks for the LC3B channel (EGFP-LC3B). The mitochondrial channel (gfap-DsRed2-mito) was converted to a binary mask using the "default" thresholding method. The "Analyze Particles" function was then used for each channel to filter out particles $<0.1$ $\mu \mathrm{m}^{2}$. The "AND" function of the Image Calculator was used to create a new $z$-stack containing only the points in each $z$ plane occupied by both mitochondria and LC3B. Analyze Particles was then used to measure the surface area of the particles in each plane of the new colocalization $z$-stack, as well as the mitochondrial $z$-stack. By measuring colocalization area in each plane, we avoid false positives from particles close in the $x / y$ dimension, but separated by several micrometers in the $z$ dimension. Colocalization area was normalized to total mitochondrial area in each plane, and mean values from all planes were calculated for each astrocyte. All groups were included in $\geq 3$ experiments, with slice cultures prepared from $\geq 3$ separate animals. Each slice was considered an $n$ of 1 (2-4 slices/group/experiment, 2 astrocytes/slice).

Live calcium imaging. Live recordings of the plasma-membranetargeted genetic calcium sensor Lck-GCaMP-6S and minimal-GFAPpromoter-driven, mitochondrially targeted DsRed2 (gfap-DsRed 2 -mito) in distal astrocytic processes were acquired using the $40 \times$ objective (and 4-5× digital zoom) with 488 and $546 \mathrm{~nm}$ lasers, respectively. Hypertrophic reactive astrocytes were avoided. Twenty-four hours after injury, slices were excised from membrane inserts with a scalpel and placed face-down on a coverslip at the bottom of a flow-through chamber in the microscope stage. The slice was submerged in ACSF (in mM: $130 \mathrm{NaCl}, 3 \mathrm{KCl}, 1.25 \mathrm{NaH}_{2} \mathrm{PO}_{4}, 26 \mathrm{NaHCO}_{3}, 10$ glucose, $1 \mathrm{MgCl}_{2}, 2$ $\mathrm{CaCl}_{2}, \mathrm{pH} 7.3$ ), constantly bubbled with $95 \% \mathrm{O}_{2} / 5 \% \mathrm{CO}_{2}$ and heated to $35^{\circ} \mathrm{C}$, and continuously flowing at $1-2 \mathrm{ml} / \mathrm{min}$. Ten minute recordings were acquired from a single $z$-plane at $512 \times 512$ pixels/frame with a digital zoom $(4-5 \times)$ sufficient to achieve a sampling rate of $1 \mathrm{~Hz}$. Recordings were excluded from analysis if the process drifted out of frame or out of the $z$-plane. In FIJI, automated background and noise (despeckle median filter) subtraction were performed for each channel of the image time-stack, and then the channels were merged to perform rigid alignment (StackReg plugin) to correct for lateral drift during the recording period. After alignment, channels were split again, and copies of the files were assigned randomized numeric file names for blinded analysis. An ROI was traced along the process using the segmented line tool, and the "Stack Profile Data" plugin (Ver. 1.0, 24-Sept.-2010, Mi- chael Schmid) was used to generate an Excel table of intensity values for each pixel along the ROI, with each frame as a column. Each pixel was then converted to $\triangle F / F 0$ to generate a new table by first subtracting and then dividing by the mean of all pixels throughout the recording ( F0). Conversion to $\triangle F / F 0$ helps to isolate the signal and allow comparison between separate recordings in which raw fluorescence intensities can vary greatly. Spatial zones of activity, defined as areas in which $\Delta F / F 0$ was $>0$, were identified. Spikes were identified within zones of activity as spans of time in which the $\Delta F / F 0$ was greater than the mean $\Delta F / F 0$ minus the $\mathrm{SD}$ within that zone of activity. In zones of activity containing largespread extramitochondrial spikes overlapping smaller mitochondrially centered $\mathrm{Ca}^{2+}$ events, the extramitochondrial spikes were isolated by only including times at which the spread was $>1 \mathrm{SD}$ above the mean.

Mean values for $\Delta F / F 0$, spread (micrometers), duration (seconds), and frequency (spikes/min) were calculated for each zone of activity. Zones of activity were classified as either mitochondrially centered (overlapping and contacting only one mitochondrion) or extramitochondrial (traversing extramitochondrial space, and contacting $\geq 2$ mitochondria), and means were calculated for each category for each recording. A single process from each slice was examined and considered an $n$ of 1 . Recordings were acquired on 4 separate days and from slices prepared from $\geq 4$ separate animals for each group.

Statistical analyses. Values reported in the Results section are mean \pm SEM, unless otherwise noted. All statistical analyses were performed using Graph Pad Prism 6. Means were compared by Student's $t$ test for two groups, or one-way ANOVA with Bonferroni's correction for multiple comparisons when comparing $>2$ groups. To test for assumptions of normality and equal variance we used the Kolmogorov-Smirnov and Brown-Forsythe tests, respectively. Data from one control slice (see Fig. 6) were excluded because high mito-EGFP expression masked small spaces between mitochondria, leading to mitochondrial lengths $>2$ SDs above the mean. To test for differences between the likelihoods of extramitochondrial spikes being confined between two mitochondria, contingency tables were constructed and pairs of groups were compared by Fisher's exact test, with Bonferroni's correction applied to calculated $p$ values. Fluorescence traces (see Fig. 8A,B) were constructed in Origin software (Microcal) for display purposes only.

\section{Results}

Astrocytes in organotypic hippocampal slice cultures maintain the highly branched morphologies that are observed in vivo (Benediktsson et al., 2005). Using this system, we and others have shown that mitochondria are found throughout processes and $\sim 20-40 \%$ are mobile. The mitochondria are immobilized near clusters of GLT1 and synapses, and they shape $\mathrm{Ca}^{2+}$ signaling (Jackson et al., 2014; Jackson and Robinson, 2015; Stephen et al., 2015). These slice cultures are also widely used to study secondary pathology after global I/R injury by using transient OGD (Bonde et al., 2005; Noraberg et al., 2005; Ahlgren et al., 2011). To date, the effects of OGD on mitochondria and $\mathrm{Ca}^{2+}$ signaling in astrocytic processes have not been examined. We biolistically transfected astrocytes with fluorescent markers to achieve sparse labeling, which is ideal for imaging individual astrocytes and their processes. In previous studies, we used slices maintained in culture for only $4 \mathrm{~d}$. In the present study, the slices were maintained in culture for 2 weeks to develop sensitivity to excitotoxic insults (Ahlgren et al., 2011).

Astrocytes were transfected with mitochondrially targeted EGFP (Rizzuto et al., 1995; for review, see Tsien, 1998) and palmitoylated mcherry under the control of the minimal GFAP promoter. Under these conditions, astrocytes can be easily identified (Jackson et al., 2014). These slices were subjected to $30 \mathrm{~min}$ of OGD and fixed at various time points for subsequent imaging analysis. Unlike most assays for cell death, the nuclear stain DAPI is compatible with paraformaldehyde fixation and its excitation/ emission spectra does not interfere with imaging of the fluoro- 

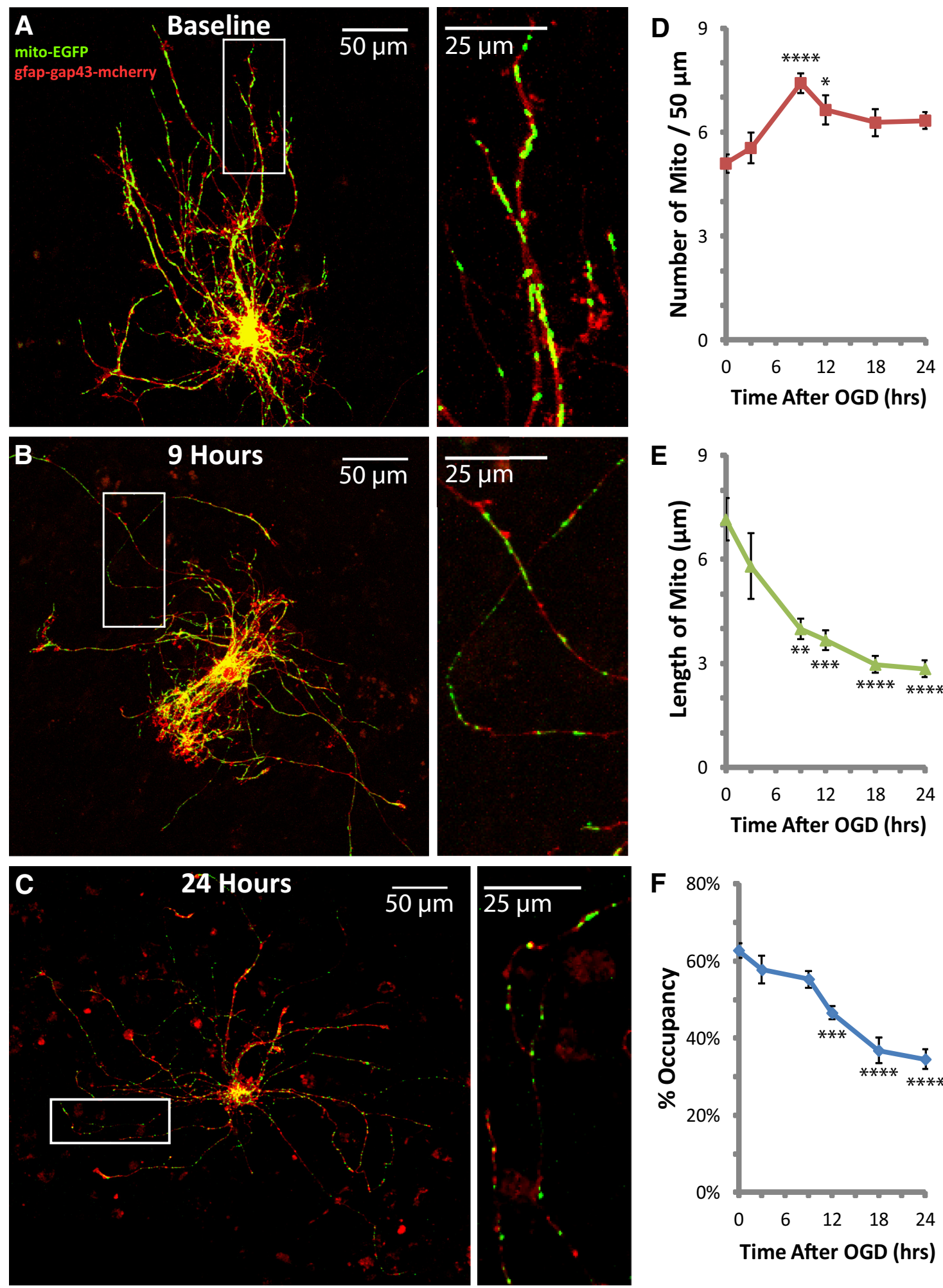

Time After OGD (hrs)

Figure 2. Thirty minutes of OGD caused delayed fragmentation and reduced occupancy of mitochondria in astrocytic processes. The same slices used for analyses of DAPI (Fig. 1) were also used to analyze mitochondria in astrocytic processes. $\boldsymbol{A}-\boldsymbol{C}$, Representative images of fluorescently labeled mitochondria (green) and plasma membrane (red) in astrocytes fixed at baseline $(\boldsymbol{A})$, the onset of mitochondrial fragmentation at $9 \mathrm{~h}(\boldsymbol{B})$, and peak mitochondrial loss at $24 \mathrm{~h}$ after $0 \mathrm{GD}(\boldsymbol{C}$. Insets provide magnified views of mitochondria in astrocytic processes. $\boldsymbol{D}-\boldsymbol{F}$, Change in the mean number of mitochondria $/ 50 \mu \mathrm{m}(\boldsymbol{D})$, length of mitochondria in micrometers $(\boldsymbol{E})$, and percentage occupancy of processes by mitochondria $(\boldsymbol{F})$ during the $24 \mathrm{~h}$ period following $30 \mathrm{~min} 0 \mathrm{GD}$ injury. All groups were included in $\geq 3$ experiments, with slice cultures prepared from $\geq 3$ separate animals. $n=7-15$ slices/group ( $2-4$ slices/group/experiment, 2 astrocytes/slice, 3 processes/astrocyte). Error bars indicate SEM. ${ }^{*} p<0.05,{ }^{* *} p<0.01,{ }^{* * *} p<0.001,{ }^{* * * *} p<0.0001$ compared with baseline by one-way ANOVA with Bonferroni's correction for multiple comparisons. Mean values for Baseline (no insult/no incubation) and a $24 \mathrm{~h}$ Control group (no insult/24 $\mathrm{h}$ incubation) were not different (data not shown). 
phores used throughout this study (e.g., EGFP, mcherry, or DsRed2). It allows for quantification of nuclear condensation and cell number to provide accurate measurement of cell death/loss (Bonde et al., 2002; Lei et al., 2008; Rininger et al., 2012; Zhou et al., 2013; Woeffler-Maucler et al., 2014), and is particularly useful in slice cultures containing phagoctytic microglia that can clear away dead cells. As was previously observed, this insult caused a delayed loss of neurons (Fig. 1), and this damage was selective for area CA1 (data not shown; Bonde et al., 2005; Noraberg et al., 2005; Ahlgren et al., 2011). Figure $1 A, B$ provides representative examples of the effects of transient OGD on DAPI staining in area CA1. There was a significant reduction in cell density at 12,18 , and $24 \mathrm{~h}$ after OGD in stratum pyramidale, the neuronal cell-body layer of CA1 (Fig. $1 C$; Bonferroni's corrected $p=0.0350$ for Baseline vs $12 \mathrm{~h}, p<0.0001$ for Baseline vs 18 or $24 \mathrm{~h} ; n=6-12$ slices/group). Cell density at $18 \mathrm{~h}$ was also significantly lower compared with 3 or $9 \mathrm{~h}$ (Bonferroni's corrected $p=0.0001$ or 0.0281 respectively; $n=6-12$ slices/group), and at $24 \mathrm{~h}$ cell density was significantly lower compared with slices fixed 3,9 , or $12 \mathrm{~h}$ after OGD (Bonferroni's corrected $p<0.0001, p=$ 0.0025 , or $p=0.0396$, respectively; $n=$ 6-12 slices/group). While optimizing this injury model, we used the cellimpermeable nucleic acid dyes propidium iodide or TO-PRO-3 to monitor cell death in CA1, and observed a similar time course to that observed with the DAPI method (three independent preliminary experiments; data not shown). These results strongly indicate a delayed, timedependent loss of CA1 pyramidal cells.

In the DAPI-stained slices, we examined the effects of OGD on mitochondria in the processes of astrocytes in stratum radiatum and pyramidale. As observed by others, we rarely found signs of reactive gliosis within $24 \mathrm{~h}$ of the insult (Ouyang et al., 2007), and therefore we excluded the few cells that appeared obviously hypertrophic. In control slices (Baseline), there were $5.1 \pm 0.3$ mitochondria per $50 \mu \mathrm{m}$ with an average length of $7.2 \pm 0.6 \mu \mathrm{m}$, occupying $62.7 \pm 1.9 \%$ of each astrocytic process ( $n=7-15$ slices/group; Fig. $2 A, D-F)$. These values are higher than what we observed previously (average length $\sim 3 \mu \mathrm{m}$ and occupancy $\sim 45 \%$ ), perhaps because we used younger slice cultures and focused only on distal regions of processes in previous studies (Genda et al., 2011; Jackson et al., 2014). The numbers of mitochondria, the lengths of the mitochondria, and the occupancy of processes by mitochondria were not significantly different in slices $3 \mathrm{~h}$ after OGD when compared with baseline. By $9 \mathrm{~h}$, the number of mitochondria per $50 \mu \mathrm{m}$ was increased by $\sim 50 \%$ (Bonferroni's corrected $p<0.0001 ; n=7-15$ slices/group), and the length of mitochondria was decreased by $\sim 50 \%$ (Bonferroni's corrected $p=0.0010 ; n=7-15$ slices/ group), but the percentage of the process occupied by mitochondria (percent occupancy) remained unchanged relative to baseline (Fig. 2B,D-F). The transient increase in the number of mitochondria concurrent with a decrease in the size of mitochondria is frequently referred to as fragmentation; this process generally precedes degradation (for review, see Itoh et al., 2013; Lemasters, 2014). The mean length of mitochondria continued to decrease to less than half of the baseline value by $24 \mathrm{~h}$ (Fig. 2C,E). The number of mitochondria was no longer significantly higher than baseline after $12 \mathrm{~h}$, which is consistent with degradation of fragmented mitochondria. Also consistent with degradation, the mean percentage of process length occupied by mitochondria (referred to as percentage occupancy) was significantly reduced to $46.5 \pm 1.7 \% 12 \mathrm{~h}$ after OGD (Bonferroni's corrected $p=$ $0.0002 ; n=7-15$ slices/group), progressing to approximately half of that observed in controls ( $34.5 \pm 2.6 \%$ occupancy) by $24 \mathrm{~h}$ (Fig. 2C,F). Scholl analysis of astrocyte morphology revealed 

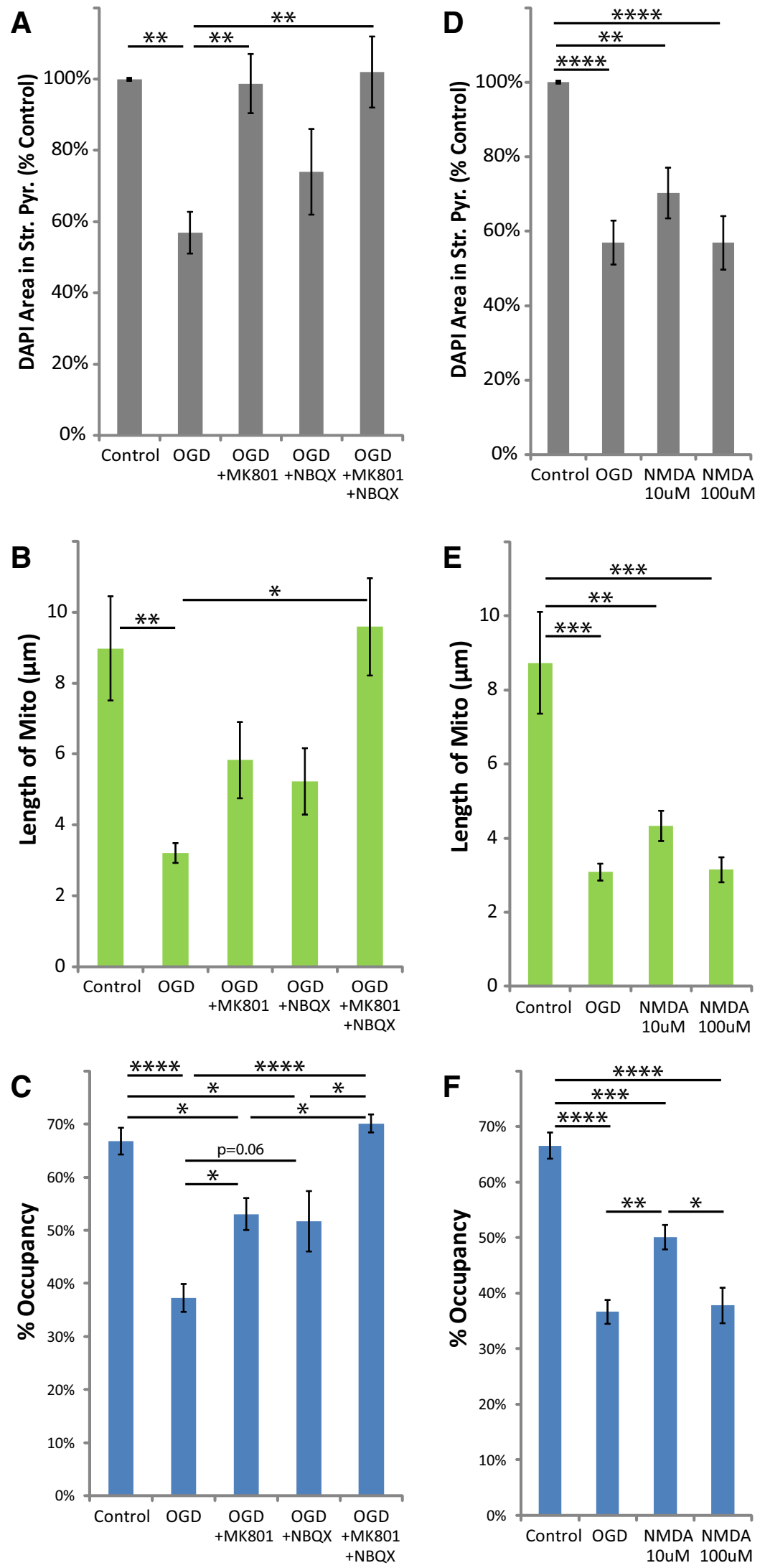

Figure 4. MK801 or NBQX blocked, and stimulating NMDARs mimicked the loss of astrocytic mitochondria after 0GD. Hippocampal slice cultures with astrocytes expressing mitochondrially targeted EGFP and plasma-membrane-targeted mcherry were fixed in 4\% paraformaldehyde $24 \mathrm{~h}$ after 30 min OGD, NMDA (10 or $100 \mu \mathrm{m})$, or control treatment. OGD slices were treated 30 min before insult, during the $30 \mathrm{~min}$ insult, and during the $24 \mathrm{~h}$ recovery period either with no drug, with $10 \mu \mathrm{m}$ MK801, with $20 \mu \mathrm{M}$ NBQX, or with both MK801 and NBQX. A-C, Effects of iGluR antagonists and OGD on mean cell density in stratum pyramidale mean ramification index values ranging from 1.2 to 1.8 , with no significant differences between time points (one-way ANOVA $p=0.80 ; n=4-8$ cells per time point), indicating that the complex morphology of astrocytic processes was maintained while mitochondria were lost.

Mitochondria are degraded through a specialized form of autophagy termed mitophagy (Lemasters, 2005). Colocalization of the autophagosome marker LC3B with mitochondria provides a more selective measure of mitophagy compared with assays for overall autophagy (Wong and Holzbaur, 2014). We cotransfected EGFPtagged LC3B with mitochondrially targeted DsRed 2 to measure colocalization of astrocytic mitochondria and autophagosomes in individual planes of confocal image stacks (40× objective; numerical aperture 1.3; Fig. 3). Confocal image stacks of astrocytes containing fluorescently labeled autophagosomes (EGFP-LC3B; green) and mitochondria (gfap-DsRed2-MITO; red) were compressed into two-dimensional images for display purposes (Fig. $3 A, B$ ). In neurons, autophagosomes form around mitochondria in distal neurite tips, and subsequent lysosomal cargo degradation occurs during retrograde transport to the cell body (Maday et al., 2012). Since mitophagy is a transient process, we used BfA, an inhibitor of the vacuolar $\mathrm{H}^{+}$-ATPase, to prevent maturation of lysosomes (for review, see Dröse and Altendorf, 1997) and allow for accumulation of the mitophagy signal in processes and cell bodies. In control slices, BfA did not significantly alter astrocytic mitochondria or reduce the density of DAPIlabeled cells for $\leq 24 \mathrm{~h}$. As is observed in neurons (Maday et al., 2012), we observed low levels of LC3B/mitochondria colocalization in astrocytes in control slices, consistent with constitutive low-level mitophagy (Fig. 3C). At $9 \mathrm{~h}$ after OGD, when there is evidence for mitochondrial fragmentation but preceding a decrease in occupancy (Fig. $2 D-F)$, there is no evidence for increased colocalization of EGFP-tagged LC3B and mitochondrial DsRed2 (Fig. 3C). However,

\footnotetext{
$(\boldsymbol{A})$, mitochondrial length in processes (micrometers; $\boldsymbol{B})$, and percentage occupancy of processes by mitochondria (C). D-F, Effects of acute NMDA insult on mean cell density in stratum pyramidale (D), mitochondrial length (micrometers; $\boldsymbol{E}$ ), and percentage occupancy of processes by mitochondria $(\boldsymbol{F})$. All groups were included in $\geq 3$ experiments, with slice cultures prepared from $\geq 3$ separate animals. $n=6-13$ slices/group (2-4 slices/group/experiment, 2 astrocytes/slice, 3 processes/astrocyte). Error bars indicate SEM. ${ }^{*} p<0.05,{ }^{* *} p<0.01,{ }^{* *} p<0.001,{ }^{* * *} p<$ 0.0001 compared by one-way ANOVA with Bonferroni's correction for multiple comparisons.
} 
at $24 \mathrm{~h}$ after OGD, when occupancy was decreased to $\sim 50 \%$ of control (Fig. $2 F$ ), we observed a significant accumulation of mitochondria-containing autophagosomes in the cell body and out in processes (Fig. $3 B, C)$. This increased signal was not observed in the absence of BfA, providing evidence that the mitochondria-containing autophagosomes are degraded when lysosomal maturation progresses normally.

To probe the mechanisms behind this effect on astrocytic mitochondria, we examined the role of iGluRs (Fig. 4). As previously observed, neuronal cell loss was completely blocked by the NMDAR antagonist MK801 (Bonde et al., 2005; Fig. $4 A$ ). The protective effect of AMPAR antagonist NBQX was variable, and DAPI staining in stratum pyramidale was not significantly different from that in control or OGD groups. Only the combination of both MK801 and NBQX significantly blocked the reduction in mitochondrial length observed after OGD (Fig. 4B). Either drug individually attenuated the loss of mitochondria (change in percentage occupancy), but only the combination of both drugs completely blocked the loss of mitochondria (Fig. 4C). Transient NMDA (30 min) caused a loss of DAPI staining comparable to that observed after OGD (Fig. 4D). It also mimicked the effects of OGD on astrocytic mitochondria, causing a significant reduction in mitochondrial length and a decrease in mitochondrial occupancy (Fig. 4E,F). Together, these studies demonstrate that activation of iGluRs is both necessary and sufficient to induce the delayed loss of astrocytic mitochondria observed after OGD. These studies suggest that either excessive activation of iGluRs on astrocytes is responsible for the loss of mitochondria or that activation of neuronal iGluRs results in release of one or more substances that subsequently cause a loss of mitochondria in astrocytic processes.

Activation of iGluRs increases glutamate release in vitro and in vivo (for review, see Mayer and Westbrook, 1987). To further test for the involvement of neuronal glutamate release, we separately blocked action potentials using the voltage-gated $\mathrm{Na}^{+}$ channel blocker TTX ( $1 \mu \mathrm{M})$, or vesicular neurotransmitter release using the $\mathrm{N}$-type $\mathrm{Ca}^{2+}$ channel blocker ziconotide $(0.5 \mu \mathrm{M})$. These drugs block glutamate release and neuronal death after NMDA exposure in similar models of $\mathrm{I} / \mathrm{R}$ injury, both in vitro and in vivo (Valentino et al., 1993; Buchan et al., 1994; Dijk et al., 1995; Pringle et al., 1996; Strijbos et al., 1996). We found that they blocked OGD-induced or NMDA-induced
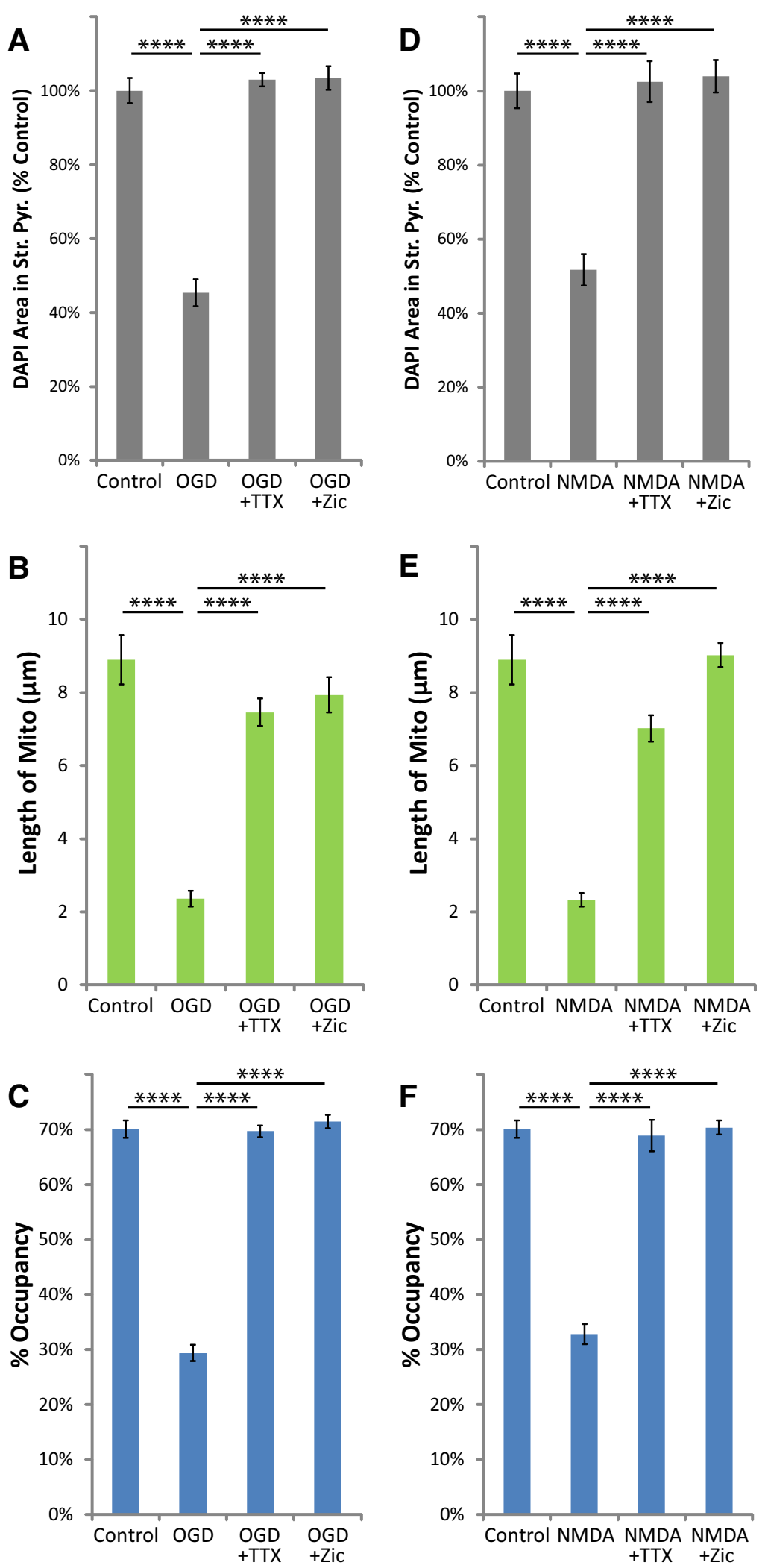

Figure 5. TTX or ziconotide blocked the loss of astrocytic mitochondria after OGD or NMDA injury. Hippocampal slice cultures with astrocytes expressing mitochondrially targeted EGFP and plasma-membrane-targeted mcherry were fixed in 4\% paraformaldehyde $24 \mathrm{~h}$ after 30 min OGD,NMDA (100 $\mu \mathrm{m})$, or control treatment. OGD and NMDA slices were treated 30 min before insult, during the 30 min insult, and during the $24 \mathrm{~h}$ recovery period either with no drug, with $1 \mu \mathrm{m} \mathrm{TTX}$, or with $0.5 \mu \mathrm{m}$ ziconotide. $\boldsymbol{A}-\boldsymbol{F}$, Mean cell density in stratum pyramidale, mitochondrial length in processes (micrometers), and percentage occupancy of processes by mitochondria $24 \mathrm{~h}$ after $30 \mathrm{~min}$ OGD $(\boldsymbol{A}-\boldsymbol{C})$ or NMDA ( $\boldsymbol{D}-\boldsymbol{F})$ with and without TTX or ziconotide. All groups were included in $\geq 3$ experiments, with slice cultures prepared from $\geq 3$ separate animals. $n=8-12$ slices/group (2-4 slices/group/experiment, 2 astrocytes/slice, 3 processes/astrocyte). Error bars indicate SEM. ${ }^{* * *} p<0.0001$ compared by one-way ANOVA with Bonferroni's correction for multiple comparisons. 

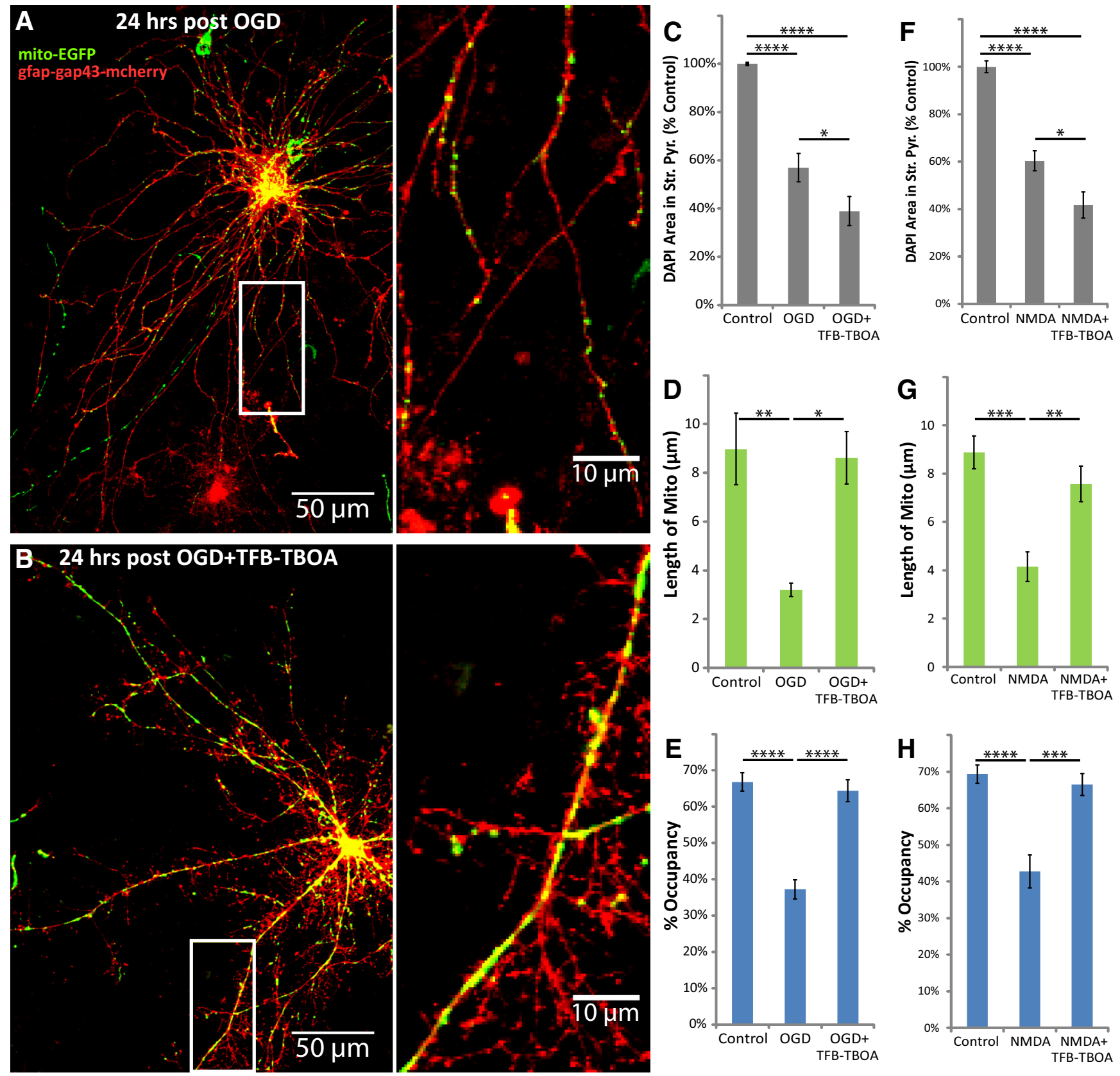

Figure 6. TFB-TBOA increased neuronal loss, but blocked the loss of astrocytic mitochondria after OGD or NMDA injury. Hippocampal slice cultures with astrocytes expressing mitochondrially targeted EGFP (mito-EGFP, green) and plasma-membrane-targeted mcherry (gfap-gap43-mcherry, red) were fixed in 4\% paraformaldehyde $24 \mathrm{~h}$ after a $30 \mathrm{~min} 0 \mathrm{GD}$, NMDA (100 $\mu \mathrm{M}$ ), or control treatment. OGD and NMDA slices were treated $30 \mathrm{~min}$ before insult, during the $30 \mathrm{~min}$ insult, and during the $24 \mathrm{~h}$ recovery period either with no drug or with $3 \mu \mathrm{m}$ TFB-TBOA. $\boldsymbol{A}, \boldsymbol{B}$, Representative images of fluorescently labeled mitochondria (green) and plasma membrane (red) in astrocytes fixed $24 \mathrm{~h}$ after OGD $(\boldsymbol{A})$ or OGD in the presence of TFB-TBOA (B). $C-\boldsymbol{H}$, Mean cell density in stratum pyramidale, mitochondrial length in processes (micrometers), and percentage occupancy of processes by mitochondria $24 \mathrm{~h}$ after 30 min $0 G D(C-E)$ or NMDA $(\boldsymbol{F}-\boldsymbol{H})$ insult with or without TFB-TBOA. All groups were included in $\geq 3$ experiments, with slice cultures prepared from $\geq 3$ separate animals. $n=8-12$ slices/group (2- 4 slices/group/experiment, 2 astrocytes/slice, 3 processes/ astrocyte). Error bars indicate SEM. ${ }^{*} p<0.05,{ }^{* *} p<0.01,{ }^{* * *} p<0.001,{ }^{* * * *} p<0.0001$ compared by one-way ANOVA with Bonferroni's correction for multiple comparisons. Insets provide magnified views of mitochondria in astrocytic processes.

loss of DAPI staining from stratum pyramidale (Fig. $5 A, D$ ). These drugs also blocked the reduction of mitochondrial size (Fig. $5 B, E$ ) and occupancy (Fig. $5 C, F$ ) in astrocytic processes $24 \mathrm{~h}$ after OGD or exposure to NMDA. These results offer support for the involvement of glutamate-induced glutamate release in the delayed fragmentation and degradation of astrocytic mitochondria observed in this model of $\mathrm{I} / \mathrm{R}$ injury.

Given that astrocytic glutamate transporter activity regulates mitochondrial mobility in processes (Jackson et al., 2014; Ug- bode et al., 2014), we tested the hypothesis that activation of glutamate transport contributes to the loss of mitochondria by blocking transporters with TFB-TBOA. The $\mathrm{IC}_{50}$ of TFB-TBOA for iGluRs is $>100 \mu \mathrm{M}$, and it has no effect on metabotropic glutamate receptors at $100 \mu \mathrm{M}$ (Shimamoto et al., 2004); at $3 \mu \mathrm{M}$ it should completely and selectively block glutamate transporter activity. As expected, TFB-TBOA increased the OGD-induced or NMDA-induced loss of DAPI staining in stratum pyramidale $24 \mathrm{~h}$ after insult (Fig. 6C,F), likely due to increased concentra- 

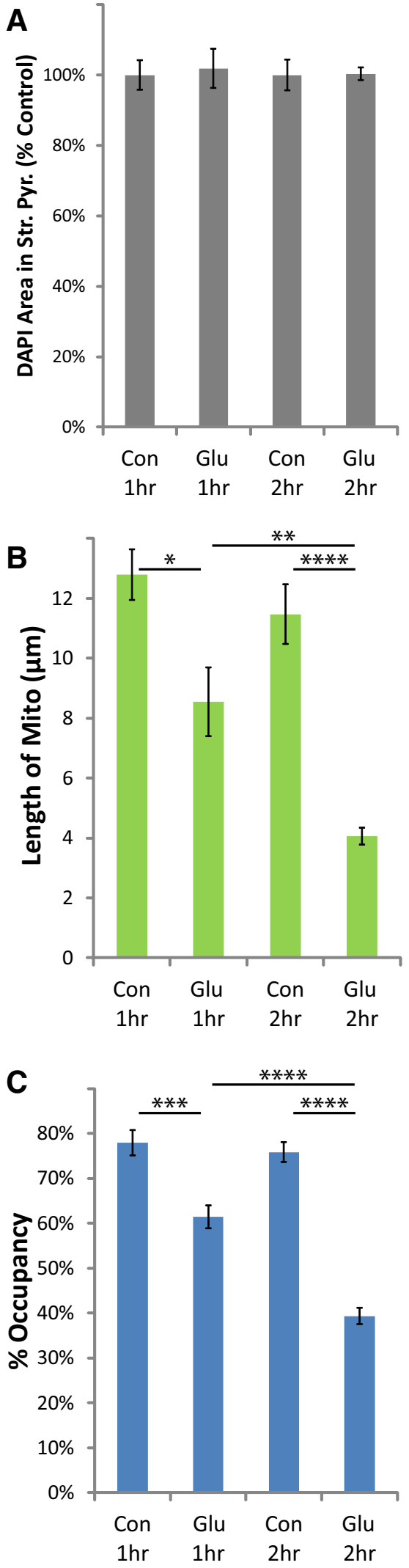

Figure 7. Glutamate caused a loss of astrocytic mitochondria in the presence of neuroprotective iGluR antagonists. Hippocampal slice cultures with astrocytes expressing mitochondrially targeted EGFP and plasma-membrane-targeted mcherry were fixed in $4 \%$ paraformaldehyde $24 \mathrm{~h}$ after a 1 or $2 \mathrm{~h}$ glutamate $(1 \mathrm{~mm})$ or control treatment. Slices were treated $30 \mathrm{~min}$ before insult, during the insult, and during the $24 \mathrm{~h}$ recovery period with MK801 $(10 \mu \mathrm{M})$ and NBQX $(20 \mu \mathrm{M})$. $\boldsymbol{A}-\boldsymbol{C}$, Mean cell density in stratum pyramidale $(\boldsymbol{A})$, mitochondrial tions of extracellular glutamate. TFB-TBOA also completely blocked the decrease in mitochondrial size and occupancy in astrocytic processes $24 \mathrm{~h}$ after OGD or NMDA (Fig. $6 D, E, G, H$ ). These data suggest that OGD induces activation of neuronal iGluRs, triggering neuronal release of glutamate (or other transporter substrates) cleared by astroglial glutamate transporters, causing mitochondrial fragmentation and degradation.

To test the hypothesis that increases in extracellular glutamate are sufficient to cause mitochondrial loss in astrocytic processes, we applied glutamate to slices in the presence of MK801 and NBQX to block neuronal death. Although micromolar glutamate is sufficient to activate iGluRs, robust glutamate uptake prevents glutamate-dependent receptor activation or cell death in slice preparations (Garthwaite, 1985; Vornov et al., 1991). In animal models of I/R injury, extracellular glutamate is elevated for $\sim 2 \mathrm{~h}$ (longer in humans) as measured by microdialysis (Dávalos et al., 1997). Therefore we examined the effects of 1 or $2 \mathrm{~h}$ exposure to $1 \mathrm{~mm}$ glutamate in the presence of iGluR antagonists. Control slices were also submerged for 1 or $2 \mathrm{~h}$ in the presence of MK801 and NBQX. There was no effect of glutamate on DAPI staining in the presence of iGluR antagonists (Fig. 7A). In contrast, glutamate caused a significant, time-dependent decrease in mitochondrial length and occupancy $24 \mathrm{~h}$ after incubation with glutamate (Fig. $7 B, C$ ). These results demonstrate that exogenous glutamate is sufficient to cause fragmentation and degradation of astrocytic mitochondria in the absence of detectable neuronal pathology.

Increased glutamate uptake through $\mathrm{Na}^{+}$-dependent transporters stimulates influx of $\mathrm{Ca}^{2+}$ via reversal of the NCX (Magi et al., 2013; Rojas et al., 2013; Jackson and Robinson, 2015). High cytosolic $\mathrm{Ca}^{2+}$ causes mitochondrial fragmentation, permeability transition, and degradation by mitophagy (for review, see Rodriguez-Enriquez et al., 2004). Drugs that selectively inhibit the reverse mode of the NCX $\left(\mathrm{Ca}^{2+}\right.$ influx $)$ are neuroprotective in models of I/R injury in vitro and in vivo (Schröder et al., 1999; Matsuda et al., 2001; Iwamoto and Kita, 2006). We found that two structurally distinct inhibitors of the reverse-mode of the NCX, KB-R7943 (15 $\mu \mathrm{M})$ or YM-244769 $(1 \mu \mathrm{M})$, attenuated the loss of DAPI staining in stratum pyramidale (Fig. $8 A$ ) as well as the reduction of mitochondrial size (Fig. $8 B$ ) and occupancy (Fig. $8 C$ ) in astrocytic processes $24 \mathrm{~h}$ after OGD. As observed with MK801, these drugs completely blocked the reduction in DAPI staining but only partially blocked the loss of astrocytic mitochondria, suggesting that mitochondrial degradation can occur in the absence of neuronal death.

CsA and FK506 work through different pathways to prevent $\mathrm{Ca}^{2+}$-induced mitochondrial permeability transition and fragmentation, and are neuroprotective in in vitro and in vivo models of $\mathrm{I} / \mathrm{R}$ injury (Nakai et al., 1997; Uchino et al., 1998; Li et al., 2000; Yokoyama et al., 2012; Trumbeckaite et al., 2013). Both drugs have been shown to selectively increase $\mathrm{Ca}^{2+}$-buffering capacity and prevent $\mathrm{Ca}^{2+}$-induced depolarization of mitochondria in astrocytes, but not in neurons in primary culture (Bambrick et al., 2006; Oliveira and Gonçalves, 2008; Kahraman et al., 2011), but at the concentrations used in the present study some effects on neuronal mitochondria could be expected. Each drug blocked the loss of DAPI

$\leftarrow$

length in processes (micrometers; $\boldsymbol{B}$ ), and percentage occupancy of processes $(\boldsymbol{C})$ by mitochondria $24 \mathrm{~h}$ after 1 or $2 \mathrm{~h}$ submersion with or without glutamate. All groups were included in four experiments, with slice cultures prepared from $\geq 4$ separate animals. $n=8$ slices/group ( $2-4$ slices/group/experiment, 2 astrocytes/slice, 3 processes/astrocyte). Error bars indicate SEM. ${ }^{*} p<0.05,{ }^{* *} p<0.01,{ }^{* * *} p<0.001,{ }^{* * *} p<0.0001$ compared by one-way ANOVA with Bonferroni's correction for multiple comparisons. 

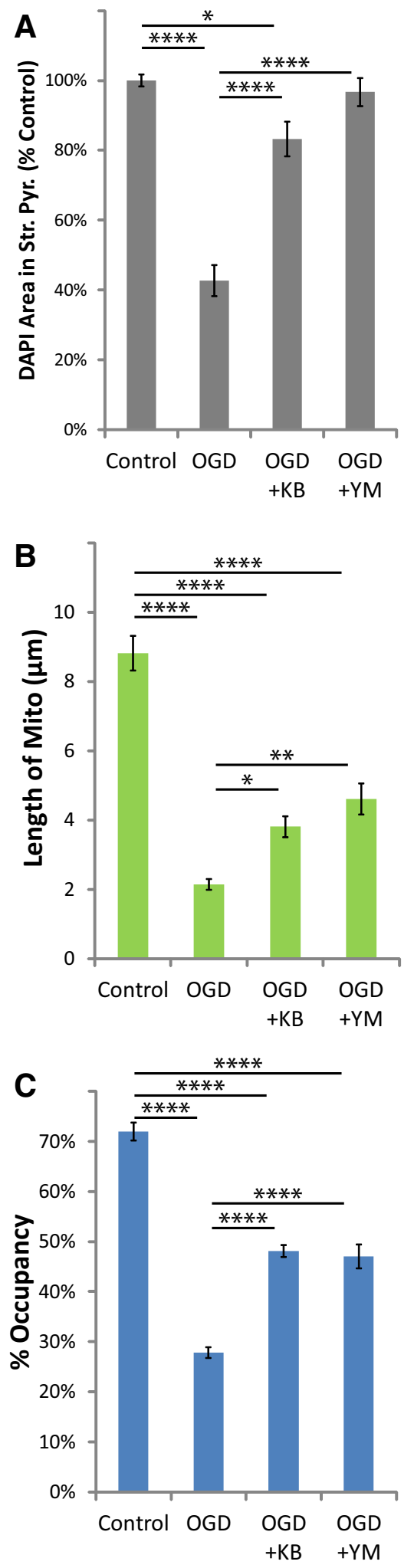

Figure 8. KB-R7943 or YM-244769 attenuated the loss of astrocytic mitochondria after OGD. Hippocampal slice cultures with astrocytes expressing mitochondrially targeted EGFP and plasma-membrane-targeted mcherry were fixed in $4 \%$ paraformaldehyde $24 \mathrm{~h}$ after a 30 min OGD or control treatment. OGD slices were treated 30 min before insult, during the 30 min insult, and during the $24 \mathrm{~h}$ recovery period either with no drug, with $15 \mu \mathrm{M}$ KB-R7943, or with $1 \mu \mathrm{m}$ YM-244769. A-C, Mean cell density in stratum pyramidale, mitochondrial length in processes (micrometers), and percentage occupancy of processes by mitochondria $24 \mathrm{~h}$ after $30 \mathrm{~min} 0 \mathrm{GD}$ with and without KB-R7943 or YM-244769. All groups were included in $\geq 3$ experiments, with slice cultures prepared from $\geq 3$ separate animals. $n=8-12$ slices/group staining in stratum pyramidale after OGD (Fig. 9C). Each of the drugs partially blocked the reduction of mitochondrial size (Fig. 9D), and almost entirely blocked loss of mitochondrial occupancy $24 \mathrm{~h}$ after OGD (Fig. 9E). CsA and FK506 exhibit direct neuronal effects, such as inhibition of calcineurin-induced nitric oxide synthase activity, which contribute to their neuroprotective effects in models of I/R injury (Dawson et al., 1993). However, it is unlikely that the neuronal effects of these drugs would reduce astrocytic mitochondrial loss, since inhibition of neuronal calcineurin by CsA has been shown to increase glutamate release (Nichols et al., 1994). Mitochondrial fragmentation precedes degradation, and this process is linked to mitochondrial depolarization (for review, see Itoh et al., 2013; Lemasters, 2014). The fact that the loss of mitochondria can be blocked while only attenuating the reduction in size suggests that fragmentation does not necessarily need to progress to degradation.

We previously reported that neuronal activity immobilizes astrocytic mitochondria near glutamate transporters and synapses through a mechanism involving glutamate uptake and reversal of the NCX (Jackson et al., 2014). More recently, our laboratory and another found that this immobilization was dependent on $\mathrm{Ca}^{2+}$ binding to motor-adaptor proteins, and that mitochondria shape $\mathrm{Ca}^{2+}$ signals in astrocytic processes (Jackson and Robinson, 2015; Stephen et al., 2015). We therefore hypothesized that loss of astrocytic mitochondria would be accompanied by increased $\mathrm{Ca}^{2+}$ signaling. For this study, DsRed2-labeled mitochondria were imaged together with spontaneous cytosolic $\mathrm{Ca}^{2+}$ signals in astrocytic processes using the high-affinity LckGCaMP-6s Ca ${ }^{2+}$ sensor $\left(K_{\mathrm{d}}=144 \mathrm{nM} ; K_{\text {off }}=1.12 \mathrm{~s}^{-1}\right.$; Chen et al., 2013).

As was recently reported (Jackson and Robinson, 2015), all of the $\mathrm{Ca}^{2+}$ signals observed overlapped with $\geq 1$ mitochondria. The sensitivity of Lck-GCaMP-6s, along with the presence of a mitochondrial label, revealed a stark anatomical difference between two types of spontaneous $\mathrm{Ca}^{2+}$ events that has not been previously described. In addition to the brief, far-reaching $\mathrm{Ca}^{2+}$ spikes traversing extramitochondrial space that have been previously reported, we also observed a nearly constant, fluctuating $\mathrm{Ca}^{2+}$ signal in the cytosol surrounding individual mitochondria (Fig. 10). Mitochondrially centered events and extramitochondrial $\mathrm{Ca}^{2+}$ spikes had similar signal amplitudes $(\Delta F / F 0$; Fig. $10 D)$. However, spread of extramitochondrial spikes covered approximately three times the distance of mitochondrially centered events (Fig. 10E). Furthermore, duration and frequency of extramitochondrial spikes were much lower than mitochondrially centered events, at approximately one-third and one-ninth of mitochondrially centered values, respectively (Fig. 10F, G). Duration was used as a measure of kinetics since the dissociation of $\mathrm{Ca}^{2+}$ from Lck-GCaMP-6s is too slow for an accurate measurement of decay.

We analyzed the effects of OGD on these two types of $\mathrm{Ca}^{2+}$ signals. The amplitudes $(\Delta F / F 0)$ of both signals were more than doubled $24 \mathrm{~h}$ after transient OGD (Fig. $11 A, B$ ). The frequencies and durations of both events were unchanged (data not shown). The spatial spread of mitochondrially centered events was decreased to half that observed in controls $24 \mathrm{~h}$ after OGD (Fig. $11 C)$; this correlates with the decrease in mitochondrial length

(2-4 slices/group/experiment, 2 astrocytes/slice, 3 processes/astrocyte). Error bars indicate SEM. ${ }^{*} p<0.05,{ }^{* *} p<0.01,{ }^{* * * *} p<0.0001$ compared by one-way ANOVA with Bonferroni's correction for multiple comparisons. 

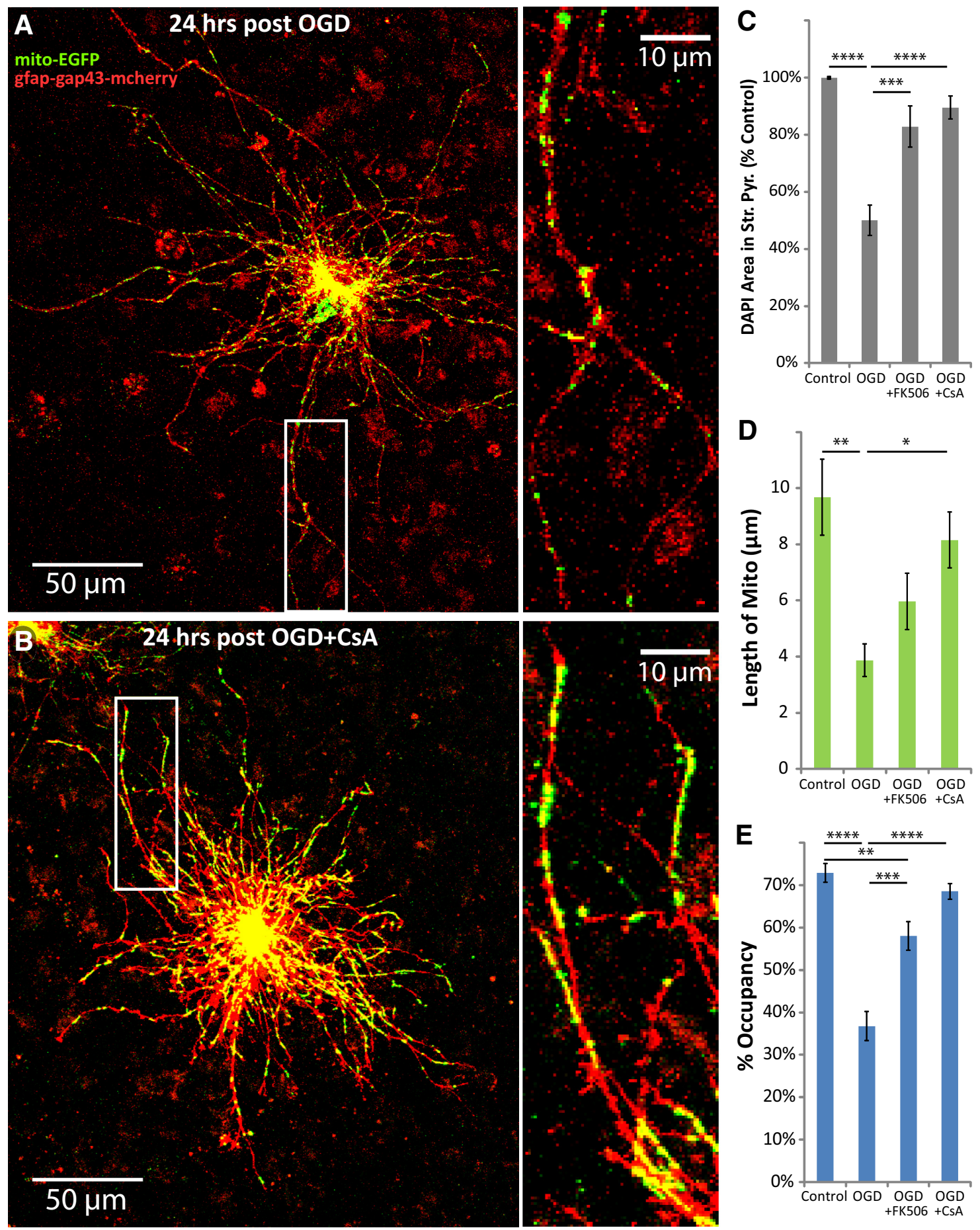

Figure 9. CSA or FK506 blocked the loss of astrocytic mitochondria after OGD. Hippocampal slice cultures with astrocytes expressing mitochondrially targeted EGFP (mito-EGFP, green) and plasmamembrane-targeted mcherry (gfap-gap43-mcherry, red) were fixed in 4\% paraformaldehyde $24 \mathrm{~h}$ after $30 \mathrm{~min} 0 \mathrm{GD}$ or control treatment. $0 \mathrm{GD}$ slices were treated 30 min before insult, during the 30 min insult, and during the $24 \mathrm{~h}$ recovery period either with no drug, with $10 \mu \mathrm{m}$ (sA, or with $10 \mu \mathrm{m}$ FK506. A, B, Representative images of fluorescently labeled mitochondria (green) and plasma membrane (red) in astrocytes fixed $24 \mathrm{~h}$ after $0 \mathrm{GD}(\boldsymbol{A})$ or $24 \mathrm{~h}$ after $0 \mathrm{GD}$ in the presence of $\mathrm{CSA}(\boldsymbol{B})$. Insets provide magnified views of mitochondria in astrocytic processes. $\boldsymbol{C}-\boldsymbol{E}$, Effects of CSA or FK506 on mean cell density in stratum pyramidale $(\boldsymbol{C})$, mitochondrial length in processes (micrometers; $\boldsymbol{D}$ ), and percentage occupancy of processes by mitochondria $(\boldsymbol{E}) 24 \mathrm{~h}$ after $30 \mathrm{~min} 0 \mathrm{GD}$. All groups were included in $\geq 3$ experiments, with slice cultures prepared from $\geq 3$ separate animals. $n=6$ slices/group (2 slices/group/experiment, 2 astrocytes/slice, 3 processes/astrocyte). Error bars indicateSEM. ${ }^{*} p<0.05,{ }^{* *} p<0.01,{ }^{* * *} p<0.001,{ }^{* * * *} p<$ 0.0001 compared by one-way ANOVA with Bonferroni's correction for multiple comparisons.

(Fig. 2E). The spread of extramitochondrial $\mathrm{Ca}^{2+}$ spikes was doubled after OGD (Fig. 11D). CsA was used to prevent the loss of astrocytic mitochondria after OGD, but CsA also changes some mitochondria-dependent $\mathrm{Ca}^{2+}$ signals (Ichas et al., 1997). To separate the effects of protecting mitochondria from direct effects on $\mathrm{Ca}^{2+}$ signaling, CsA was not present during live $\mathrm{Ca}^{2+}$ imaging. When we used CsA to prevent the loss of mitochondria in astrocytes after OGD, all effects on $\Delta F / F 0$ and spread were completely blocked (Fig. 11A-D).

To further understand the increased spread of extramitochondrial $\mathrm{Ca}^{2+}$ spikes after OGD, it is helpful to consider $\mathrm{Ca}^{2+}$ in the anatomical context of mitochondria (Fig. 12). Extramito- 

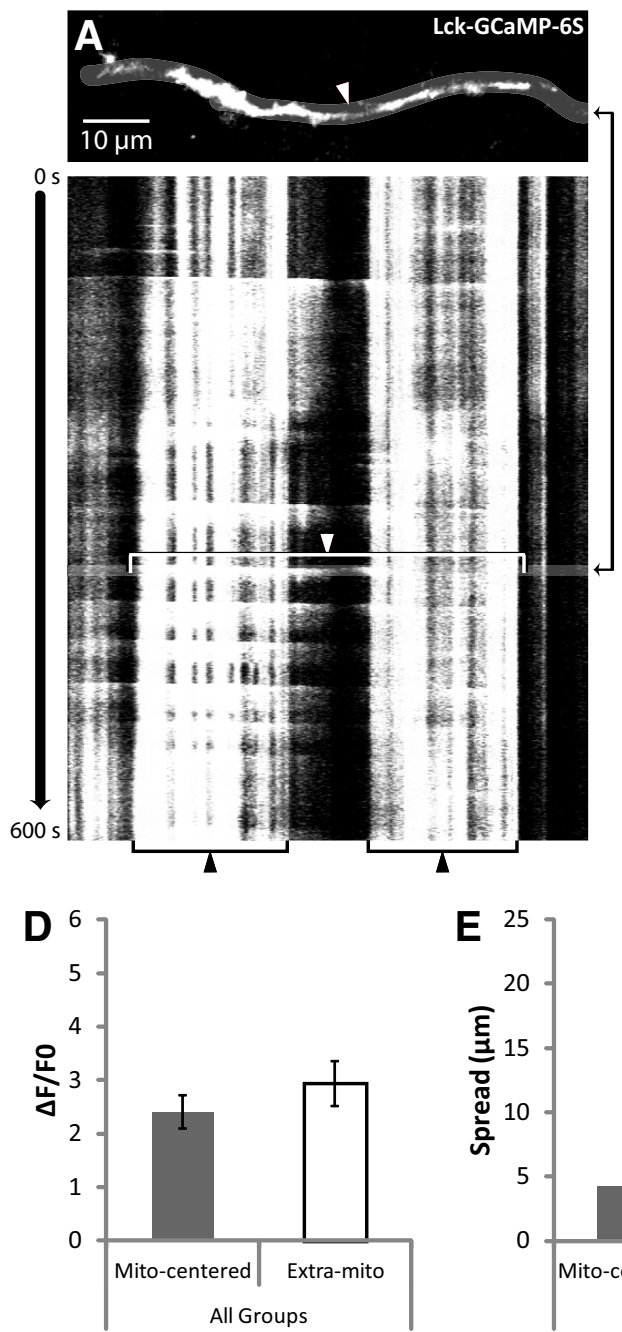
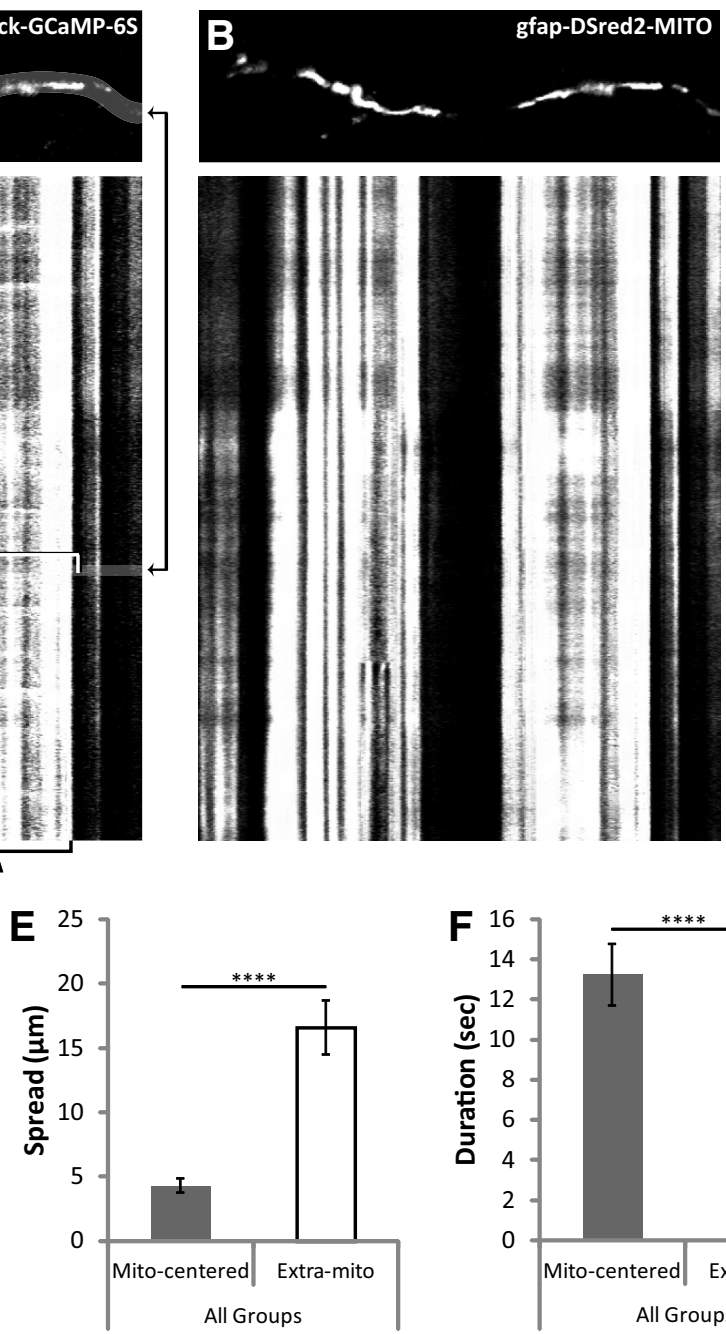
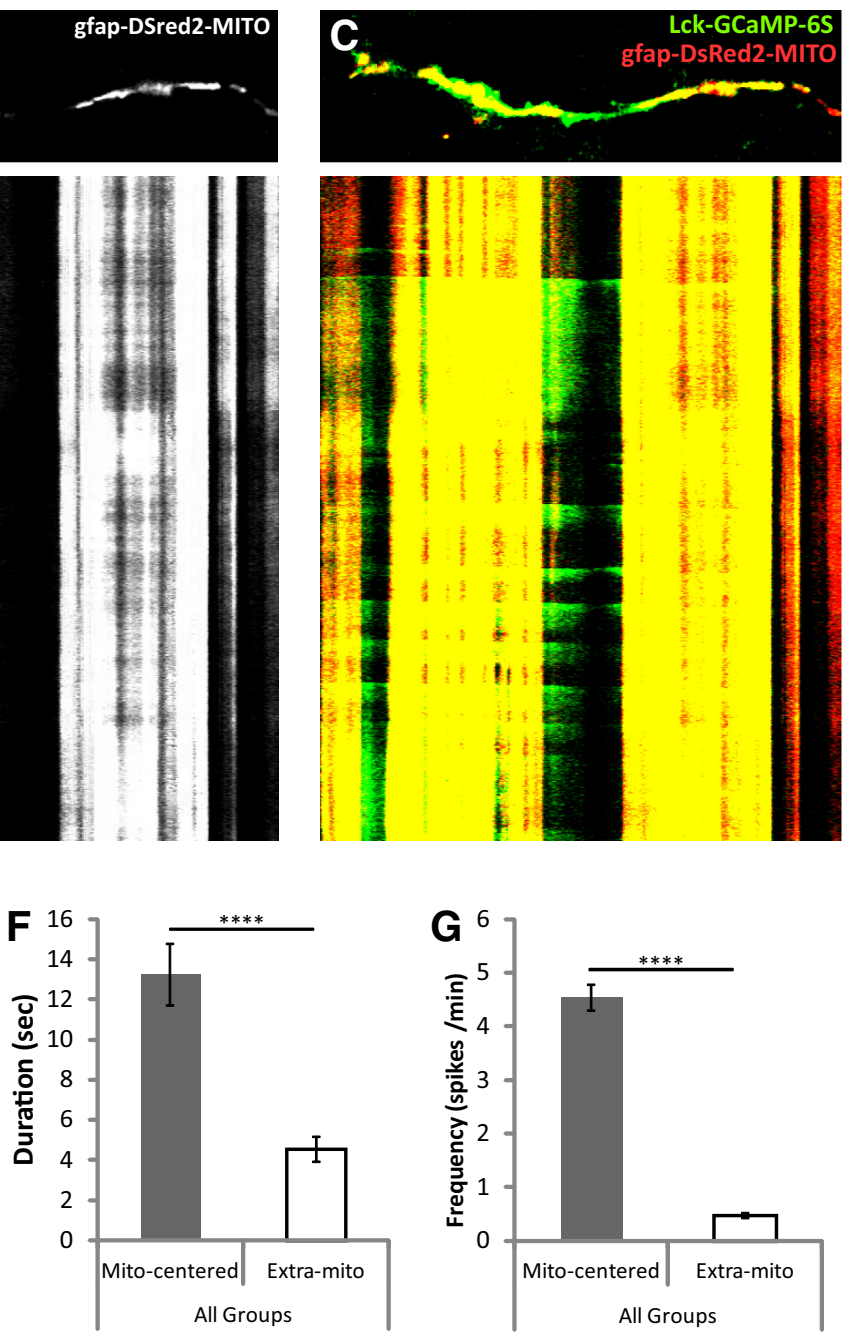

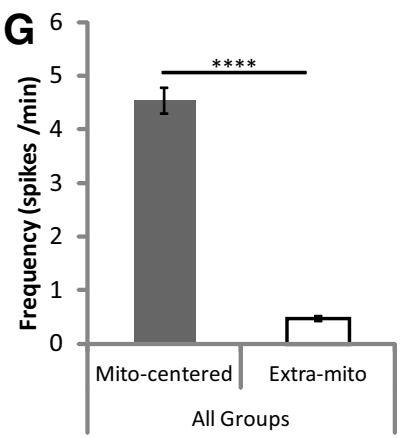

Figure 10. Spontaneous cytosolic $\mathrm{Ca}^{2+}$ signals were observed surrounding mitochondria or spanning the space between mitochondria with distinct properties. Hippocampal slice cultures with astrocytes expressing a plasma-membrane-targeted $\mathrm{Ca}^{2+}$ sensor (Lck-GCaMP-6S, green) and mitochondrially targeted DsRed2 (gfap-DsRed2-mito, red) were imaged at $1 \mathrm{~Hz}$ for $10 \mathrm{~min}$ (600 s) in a flow-through chamber $24 \mathrm{~h}$ after $0 \mathrm{GD}$ or control treatment to obtain live recordings of $\mathrm{Ca}^{2+}$ activity in astrocytic processes. OGD slices were treated 30 min before insult, during the 30 min insult, and during the $24 \mathrm{~h}$ recovery period either with no drug or with $10 \mu \mathrm{M}$ CsA, but CsA was not present during live $\mathrm{Ca}^{2+}$ imaging. $A$, Representative image of a single frame displaying an extramitochondrial $\mathrm{Ca}^{2+}$ spike (top), and a kymograph displaying both extramitochondrial (white arrow and bracket) and mitochondrially centered (black arrow and bracket) $\mathrm{Ca}^{2+}$ signals over time throughout the recording. The time at which the representative frame (top) appears in the kymograph is indicated by the black arrows to the right of the image. $\boldsymbol{B}, \boldsymbol{C}$, Corresponding mitochondrial (gfap-DsRed2-MITO) signal (B), and merged $\mathrm{Ca}^{2+}$ and mitochondrial signals (C). D-G, Comparison of mitochondrially centered and extramitochondrial $\mathrm{Ca}^{2+}$ signals by mean intensity $(\Delta F / F 0 ; \boldsymbol{D})$, spread $(\boldsymbol{E})$, duration $(\boldsymbol{F})$, and frequency $(\boldsymbol{G})$. Mitochondrially centered and extramitochondrial $\mathrm{Ca}^{2+}$ signals were pooled from Control, $0 \mathrm{GD}$, and $0 \mathrm{GD}$ plus $(\mathrm{SA}$ groups for this analysis. Means from each recording were considered an $n$ of 1 (mito-centered $n=18$, extra-mito $n=22$ ), and recordings were acquired from four separate experiments with slices prepared from $\geq 4$ different animals. Error bars indicate SEM. ${ }^{* * *} p<0.0001$ by one-way ANOVA with Bonferroni's correction for multiple comparisons.

chondrial spikes were observed in 8 of 11 recordings in both control and OGD groups. In control slices, $86 \%$ of extramitochondrial spikes were contained between two mitochondria (Fig. $12 \mathrm{~A}, \mathrm{C}$ ). Twenty-four hours after OGD, none of the extramitochondrial spikes were contained between two mitochondria; instead they all traversed multiple mitochondria (Fig. $12 \mathrm{~B}, \mathrm{C}$ ). Preventing the OGD-induced loss of mitochondria with CsA blocked this effect (Fig. 12C).

\section{Discussion}

Mitochondria in astrocytic processes are positioned near glutamate transporters and synapses through a mechanism involving neuronal activity and $\mathrm{Ca}^{2+}$-sensitive motor adaptor proteins. These mitochondria shape $\mathrm{Ca}^{2+}$ signaling (Jackson et al., 2014; Jackson and Robinson, 2015; Stephen et al., 2015). Here we present evidence that the delayed neuronal death observed in area CA1 after transient OGD was accompanied by fragmentation and autophagic degradation of mitochondria in astrocytic processes. The loss of mitochondria was associated with a dramatic increase in spontaneous $\mathrm{Ca}^{2+}$ signals in distal astrocytic processes.

\section{Mechanism of mitochondrial loss}

We show that the OGD-induced loss of astrocytic mitochondria is completely blocked by a combination of iGluR antagonists (MK-801 and NBQX), an inhibitor of neuronal action potentials (TTX), an inhibitor of vesicular glutamate release (ziconotide), a glutamate transport inhibitor (TFB-TBOA), or two different inhibitors of calcineurin (CsA or FK506). NMDA or glutamate mimicked the effect of OGD, and the NMDA-induced loss of mitochondria was blocked by TFB-TBOA. The simplest explanation for these data is that OGD triggers an iGluR-dependent increase in extracellular glutamate (or aspartate), activation of astrocytic transporters, and loss of astrocytic mitochondria. 
Previous studies have demonstrated that OGD or activation of iGluRs causes an increase in extracellular glutamate (and aspartate; Bustos et al., 1992; Dijk et al., 1995; Fujimoto et al., 2004; Bonde et al., 2005). During $30 \mathrm{~min}$ of OGD, elevated extracellular glutamate is mainly attributed to reversal of neuronal glutamate transporters and some vesicular release (for review, see Rossi et al., 2007). After reperfusion, additional periods of elevated extracellular glutamate have been observed by in vivo microdialysis in CA1, but the source(s) for this glutamate have not been identified (Yang et al., 2001). The fact that inhibitors of neuronal $\mathrm{Na}^{+}$ channels or the $\mathrm{N}$-type $\mathrm{Ca}^{2+}$ channel block the changes in astrocytic mitochondria are consistent with the notion that this glutamate is released from neuronal vesicles.

Glutamate uptake increases intracellular $\mathrm{Ca}^{2+}$ through reversed operation of plasma membrane NCXs (Magi et al., 2013; Rojas et al., 2013; Jackson and Robinson, 2015), and blocking this reversed mode after OGD attenuated the loss of astrocytic mitochondria. In other systems, coincident increases in $\mathrm{Ca}^{2+}$ and reactive oxygen species (ROS) cause mitochondrial swelling, depolarization, fragmentation, opening of the permeability transition pore, and mitophagy ( $\mathrm{He}$ and Lemasters, 2002; Kim et al., 2012). High mitochondrial $\mathrm{Ca}^{2+}$ also activates several TCA-cycle dehydrogenases that generate ROS (Denton et al., 1972; for review, see Brookes et al., 2004). Increased oxidation of glutamate itself could contribute to the loss of mitochondria via increased generation of ROS. Glutamate enters the TCA cycle through conversion to $\alpha$-ketoglutarate (for review, see McKenna, 2013). Conversion of $\alpha$-ketoglutarate to succinyl CoA by the $\alpha$-ketoglutarate dehydrogenase complex generates 2-3-fold more ROS than the other TCA-cycle dehydrogenases (Starkov et al., 2004; Tretter and Adam-Vizi, 2004). However, testing this hypothesis is difficult because inhibiting glutamate dehydrogenase or $\alpha$-ketoglutarate dehydrogenase inhibits glutamate uptake (Whitelaw and Robinson, 2013; J. C. O’Donnell, E. Krizman, and M. B. Robinson, unpublished observations).

Preventing $\mathrm{Ca}^{2+}$-induced mitochondrial depolarization with CsA or FK506 (Bambrick et al., 2006; Oliveira and Gonçalves, 2008; Kahraman et al., 2011) likely contributed to the prevention of mitochondrial loss in astrocytes after OGD. However, $\mathrm{Ca}^{2+}$-mediated activation of calcineurin can cause inflammation in astrocytes through activation of nuclear factor of activated $\mathrm{T}$ cells and
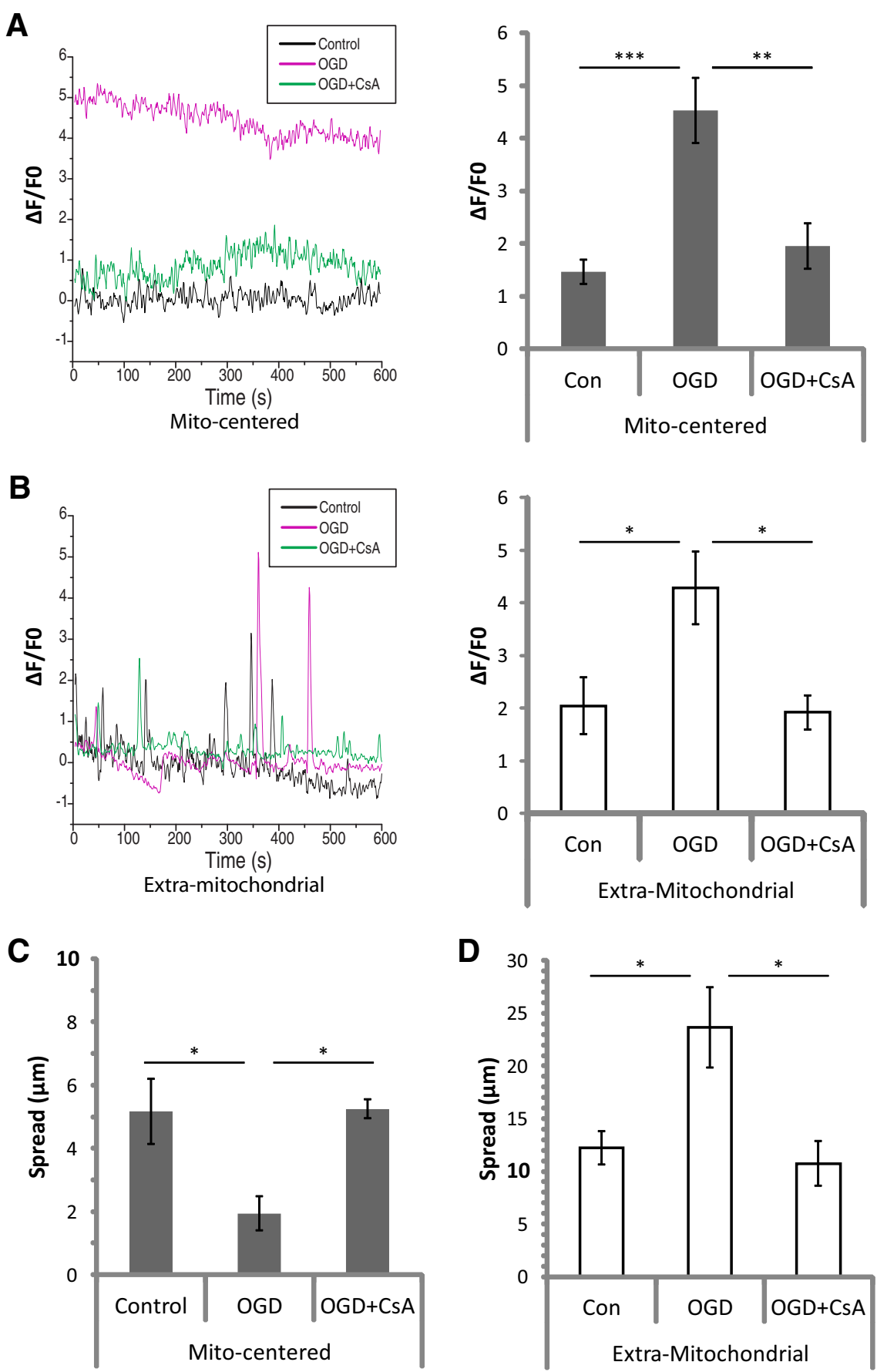

Figure 11. $\quad \mathrm{Ca}^{2+}$ signal intensity and spread were drastically altered following OGD-induced loss of mitochondria in astrocytic processes. Hippocampal slice cultures with astrocytes expressing a plasma-membrane-targeted $\mathrm{Ca}^{2+}$ sensor (Lck-GCaMP-6S) and mitochondrially targeted DsRed2 (gfap-DsRed2-mito) were imaged at $1 \mathrm{~Hz}$ for $10 \mathrm{~min}(600 \mathrm{~s})$ in a flow-through chamber $24 \mathrm{~h}$ after OGD or control treatment to obtain live recordings of $\mathrm{Ca}^{2+}$ activity in astrocytic processes. OGD slices were treated $30 \mathrm{~min}$ before insult, during the 30 min insult, and during the $24 \mathrm{~h}$ recovery period either with no drug or with $10 \mu \mathrm{M}$ CSA, but CSA was not present during live $\mathrm{Ca}^{2+}$ imaging. $A, B$, Example traces (left) and mean $\triangle F / F 0$ values (right), for $24 \mathrm{~h}$ Control (Con), OGD, or OGD plus CSA $(O G D+C S A)$ slices, in both mitochondrially centered $(\boldsymbol{A})$ and extramitochondrial $(\boldsymbol{B}) \mathrm{Ca}^{2+}$ signals. $\boldsymbol{C}, \boldsymbol{D}$, Effects of $0 G D$ or $O G D+C S A$ on mean spread among mitochondrially centered fluctuations $(\boldsymbol{C})$ and extramitochondrial spikes $(\boldsymbol{D})$. Means from each recording were considered an $n$ of 1 ( $n=5-9$ recordings/group), and recordings were acquired from four separate experiments with slices prepared from $\geq 4$ different animals. Error bars indicate SEM. ${ }^{*} p<0.05,{ }^{* *} p<0.01,{ }^{* * *} p<0.001$ by one-way ANOVA with Bonferroni's correction for multiple comparisons.

nuclear factor $\kappa$ B (for review, see Furman and Norris, 2014). The efficacy of CsA and FK506, both calcineurin inhibitors, could imply a role for inflammation in the loss of astrocytic mitochondria after transient OGD, similar to the inflamma- 
A

Calcium spike between two mitochondria
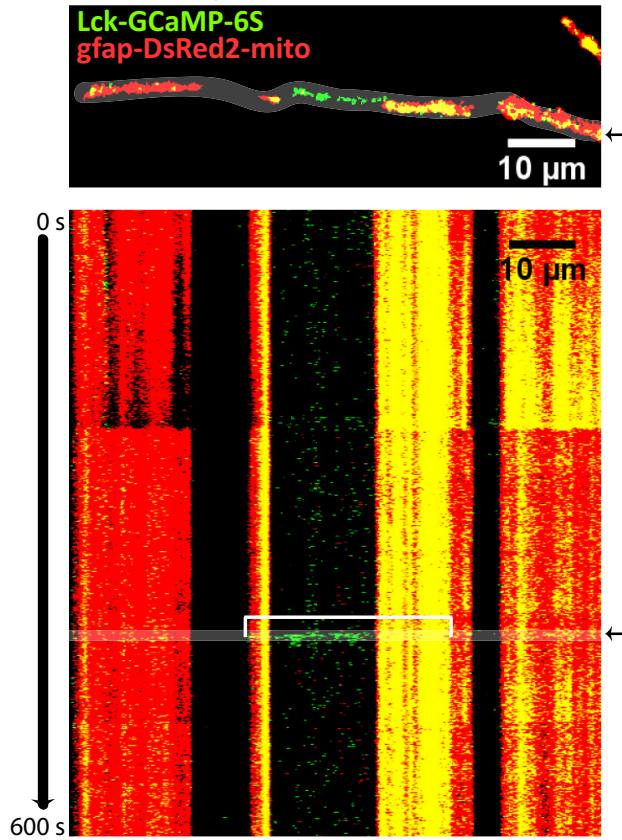

B

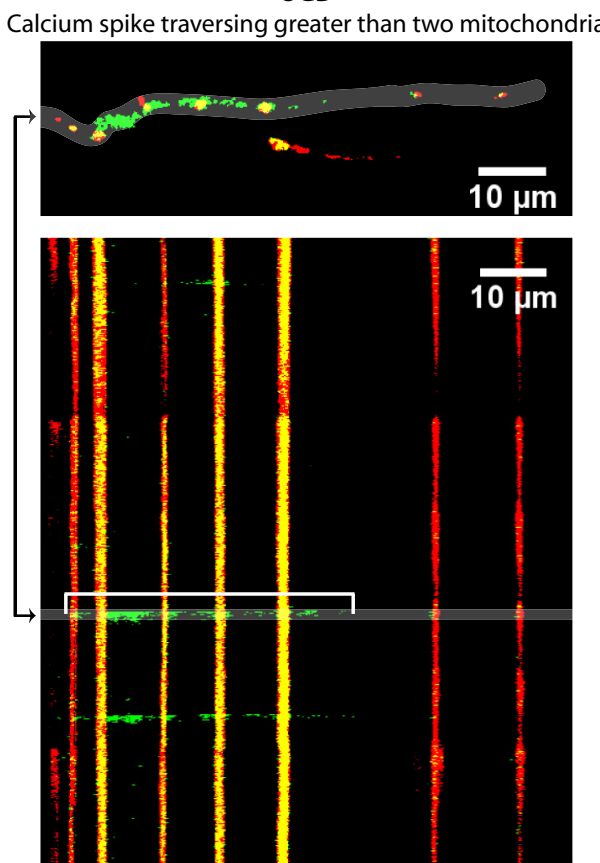

c

घetween 2 Mito $\square$ Traversing >2 Mito

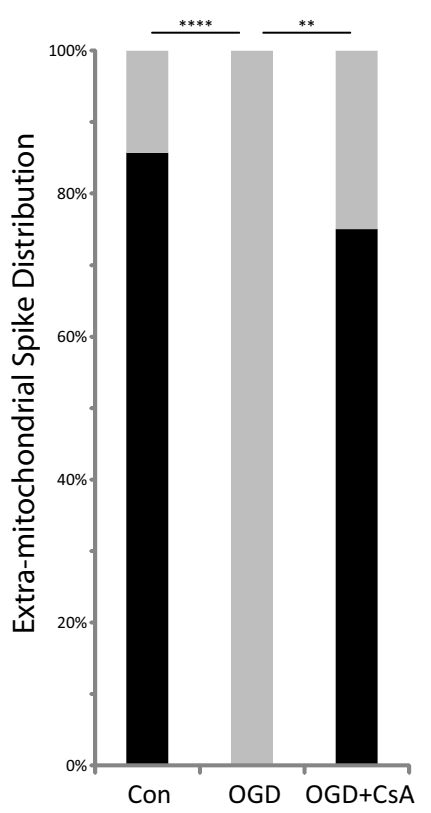

Figure 12. Extramitochondrial $\mathrm{Ca}^{2+}$ spikes were no longer contained between two mitochondria after $0 \mathrm{GD}$. Extramitochondrial spikes from experiments summarized in Figures 7 and 8 were analyzed for their anatomic relationship to mitochondria (contained between 2 mitochondria, or traversing multiple mitochondria). $\boldsymbol{A}$, Representative image of a single frame (top) displaying an extramitochondrial $\mathrm{Ca}^{2+}$ spike (LCk-GCaMP-6S, green) contained between two mitochondria (gfap-DsRed2-mito, red), and a kymograph (bottom) displaying Ca ${ }^{2+}$ and mitochondria over time throughout the recording acquired $24 \mathrm{~h}$ after control treatment, with the example spike indicated by a white bracket. $\boldsymbol{B}$, Representative image of a single frame (top) displaying an extramitochondrial $\mathrm{Ca}^{2+}$ spike (green) traversing $>2$ mitochondria (red), and a kymograph (bottom) displaying $\mathrm{Ca}^{2+}$ and mitochondria over time throughout the recording acquired $24 \mathrm{~h}$ after $0 \mathrm{GD}$, with the example spike indicated by a white bracket. The times at which the representative frames appear in the kymographs are indicated by the black arrows to the side of the image. $\mathbf{C}$, Distribution of extramitochondrial spikes classified into two categories: between two mitochondria or traversing $>2$ mitochondria. ${ }^{* *} p<0.01,{ }^{* * *} p<0.001$ by Fisher's exact test with Bonferroni's correction for multiple comparisons.

tion-dependent mitophagy observed in astrocytes after cortical stab wound (Motori et al., 2013).

\section{Consequences of mitochondrial loss and insights into $\mathrm{Ca}^{2+}$ signaling}

We observed two anatomically distinct, spontaneous $\mathrm{Ca}^{2+}$ signals in the cytoplasm of astrocytic processes, one of which has not been previously described. There were constant, fluctuating $\mathrm{Ca}^{2+}$ signals surrounding mitochondria, and brief, far-reaching spikes that traversed extramitochondrial space. The fact that photoablation of individual mitochondria causes a large transient increase in cytoplasmic $\mathrm{Ca}^{2+}$ strongly suggests that the mitochondria contain $\mathrm{Ca}^{2+}$ (Jackson and Robinson, 2015). Decreased spread of mitochondrially centered $\mathrm{Ca}^{2+}$ signals after OGD correlated with decreased mitochondrial size, implicating mitochondria as the source. With the identification of a localized $\mathrm{Ca}^{2+}$ cloud surrounding mitochondria, we suspect that mitochondria may play a role in generating $\mathrm{Ca}^{2+}$ spikes in astrocytic processes, as they do in primary culture (Parnis et al., 2013) and other cells (for review, see Rizzuto et al., 2012). While the current study was under review, Jiang et al. described two types of $\mathrm{Ca}^{2+}$ signals in astrocytic processes with similar properties to those described in the current study, but without the anatomic relationship to mitochondria (Jiang et al., 2016).

Our laboratory and those of others have recently demonstrated that mitochondria shape $\mathrm{Ca}^{2+}$ signals in astrocytic processes (Jackson and Robinson, 2015; Stephen et al., 2015). In our recent study, uncoupling oxidative ATP production with carbonyl cyanide p-trifluoromethoxyphenylhydrazone or photo-ablating mitochondria with KillerRed-mito caused a large increase in cytoplasmic $\mathrm{Ca}^{2+}$. These effects were associated with increased spatial spread, indicating that mitochondria spatially restrict these signals. OGD-induced mitochondrial loss also resulted in increased spread of extramitochondrial spikes, and the likelihood of spikes staying confined between two mitochondria went from $86 \%$ to zero after OGD. In agreement with observations from recent studies (Jackson and Robinson, 2015; Stephen et al., 2015), this suggests that mitochondria provide spatial restriction for $\mathrm{Ca}^{2+}$ signals in astrocytic processes.

A recent study using in vivo two-photon imaging in awake mice found that the spread of $\mathrm{Ca}^{2+}$ "hotspots" in astrocytic processes increased with sensory stimulation and decreased with TTX treatment (Asada et al., 2015). Another study using hippocampal cultures found that activity of local synapses is coordinated by $\mathrm{Ca}^{2+}$ signaling in astrocytic processes (Sasaki et al., 2014). Activity-driven positioning of mitochondria at glutamate transporters apposing synapses (Jackson et al., 2014), along with spatial restriction of $\mathrm{Ca}^{2+}$ signals by those mitochondria (Jackson and Robinson, 2015; Stephen et al., 2015), could represent a system for coordinating weak signals between neighboring sites of activity, while larger signals are relayed beyond neighboring mitochondria to more distant zones of activity, as was observed in response to sensory stimulation (Asada et al., 2015). Exploring this phenomenon could reveal a new mechanism for integrating local neuronal signaling events via mitochondrially segmented $\mathrm{Ca}^{2+}$ signaling in astrocytic microdomains. 


\section{Implications for $\mathrm{I} / \mathrm{R}$ injury}

Following cerebral I/R injury, the neurovascular coupling response is depressed in humans, likely impairing recovery (Salinet et al., 2015). Although the mechanisms are not fully understood, astrocytic $\mathrm{Ca}^{2+}$ signaling has been implicated in mediating neurovascular coupling (Takano et al., 2006; Dunn et al., 2013; Otsu et al., 2015), which is not surprising given the positioning of astrocytes between synapses and the vasculature, and their reliance on $\mathrm{Ca}^{2+}$ for propagating information (for review, see Parpura et al., 2012). In addition to altered neurovascular coupling, $\mathrm{Ca}^{2+}$-induced vesicular glutamate release from astrocytes has been shown to increase excitotoxic damage from seizure and stroke (Ding et al., 2007; Hines and Haydon, 2013; Takemiya and Yamagata, 2013). Increased astrocytic $\mathrm{Ca}^{2+}$ signaling with a lower threshold for induction has been observed in in vitro and in vivo models of I/R (for review, see Ding, 2014). However, none of these studies focused on the period of delayed secondary pathology, or on microdomain $\mathrm{Ca}^{2+}$ signaling in the distal astrocytic process. In the current study we provide evidence of dramatically amplified, spatially deregulated $\mathrm{Ca}^{2+}$ signaling in astrocytic processes after OGD-induced mitochondrial loss, which could disrupt neurovascular coupling and stimulate vesicular glutamate release from astrocytes during secondary neuronal pathology.

Glutamate metabolism will likely be impaired following the loss of mitochondria. The mitochondrial enzyme glutamate dehydrogenase converts glutamate to $\alpha$-ketoglutarate for entry into the TCA cycle and generation of ATP (for review, see Dienel, 2013). Glutamate dehydrogenase is enriched ( $~ 5$-fold) in astrocytes (Zaganas et al., 2001; Zhang et al., 2014), and brain-specific knock-outs demonstrate increased glucose deployment from the periphery and use in brain to compensate for the loss of glutamate as a fuel source (Karaca et al., 2015). We are currently testing the hypothesis that the loss of astrocytic mitochondria after OGD will result in a significant reduction of glutamate oxidation, which could impair recovery after I/R injury.

\section{Conclusion}

We have presented the first evidence that increased activation of iGluRs, neuronal glutamate release, and glutamate uptake into astrocytes after transient OGD causes a delayed fragmentation and autophagic degradation of mitochondria in astrocytic processes. This effect is associated with a dramatic increase in the amplitude and spread of extramitochondrial $\mathrm{Ca}^{2+}$ spikes in astrocytic processes. The removal of damaged, dysfunctional mitochondria may be beneficial for astrocyte survival. However, it may also exacerbate neuronal damage, not just through $\mathrm{Ca}^{2+}$ associated effects on neurovascular coupling and glial glutamate release, but also through the loss of astrocytic support of neurons. Astrocytes are more resilient than neurons after I/R injury, so it could be easier to target and correct their less-severe dysfunction, allowing the astrocytes to continue to support and protect neurons (for review, see Chen and Swanson, 2003; Rossi et al., 2007; Barreto et al., 2011). Healthy astrocytes providing potassium homeostasis, glutamate clearance, antioxidants, and metabolic support are in a better position to rescue neighboring neurons than any neuronally targeted therapy.

\section{References}

Ahlgren H, Henjum K, Ottersen OP, Rundén-Pran E (2011) Validation of organotypical hippocampal slice cultures as an ex vivo model of brain ischemia: different roles of NMDA receptors in cell death signalling after exposure to NMDA or oxygen and glucose deprivation. Cell Tissue Res 345:329-341. CrossRef Medline

Akerboom J, Chen TW, Wardill TJ, Tian L, Marvin JS, Mutlu S, Calderón NC,
Esposti F, Borghuis BG, Sun XR, Gordus A, Orger MB, Portugues R, Engert F, Macklin JJ, Filosa A, Aggarwal A, Kerr RA, Takagi R, Kracun S, et al. (2012) Optimization of a GCaMP calcium indicator for neural activity imaging. J Neurosci 32:13819-13840. CrossRef Medline

Albus K, Heinemann U, Kovács R (2013) Network activity in hippocampal slice cultures revealed by long-term in vitro recordings. J Neurosci Methods 217:1-8. CrossRef Medline

Asada A, Ujita S, Nakayama R, Oba S, Ishii S, Matsuki N, Ikegaya Y (2015) Subtle modulation of ongoing calcium dynamics in astrocytic microdomains by sensory inputs. Physiol Rep 3:pii:12454. CrossRef Medline

Bambrick L, Kristian T, Fiskum G (2004) Astrocyte mitochondrial mechanisms of ischemic brain injury and neuroprotection. Neurochem Res 29:601-608. Medline

Bambrick LL, Chandrasekaran K, Mehrabian Z, Wright C, Krueger BK, Fiskum G (2006) Cyclosporin A increases mitochondrial calcium uptake capacity in cortical astrocytes but not cerebellar granule neurons. J Bioenerg Biomembr 38:43-47. CrossRef Medline

Barreto G, White RE, Ouyang Y, Xu L, Giffard RG (2011) Astrocytes: targets for neuroprotection in stroke. Cent Nerv Syst Agents Med Chem 11: 164-173. CrossRef Medline

Benediktsson AM, Schachtele SJ, Green SH, Dailey ME (2005) Ballistic labeling and dynamic imaging of astrocytes in organotypic hippocampal slice cultures. J Neurosci Methods 141:41-53. CrossRef Medline

Bonde C, Noraberg J, Zimmer J (2002) Nuclear shrinkage and other markers of neuronal cell death after oxygen-glucose deprivation in rat hippocampal slice cultures. Neurosci Lett 327:49-52. CrossRef Medline

Bonde C, Noraberg J, Noer H, Zimmer J (2005) Ionotropic glutamate receptors and glutamate transporters are involved in necrotic neuronal cell death induced by oxygen-glucose deprivation of hippocampal slice cultures. Neuroscience 136:779-794. CrossRef Medline

Borgens RB, Liu-Snyder P (2012) Understanding secondary injury. Q Rev Biol 87:89-127. Medline

Brookes PS, Yoon Y, Robotham JL, Anders MW, Sheu SS (2004) Calcium, ATP, and ROS: a mitochondrial love-hate triangle. Am J Physiol Cell Physiol 287:C817-C833. CrossRef Medline

Buchan AM, Gertler SZ, Li H, Xue D, Huang ZG, Chaundy KE, Barnes K, Lesiuk HJ (1994) A selective N-type $\mathrm{Ca}(2+)$-channel blocker prevents CA1 injury $24 \mathrm{~h}$ following severe forebrain ischemia and reduces infarction following focal ischemia. J Cereb Blood Flow Metab 14:903-910. CrossRef Medline

Bustos G, Abarca J, Forray MI, Gysling K, Bradberry CW, Roth RH (1992) Regulation of excitatory amino acid release by N-methyl-D-aspartate receptors in rat striatum: in vivo microdialysis studies. Brain Res 585: 105-115. CrossRef Medline

Chen TW, Wardill TJ, Sun Y, Pulver SR, Renninger SL, Baohan A, Schreiter ER, Kerr RA, Orger MB, Jayaraman V, Looger LL, Svoboda K, Kim DS (2013) Ultrasensitive fluorescent proteins for imaging neuronal activity. Nature 499:295-300. CrossRef Medline

Chen Y, Swanson RA (2003) Astrocytes and brain injury. J Cereb Blood Flow Metab 23:137-149. CrossRef Medline

Choi DW, Rothman SM (1990) The role of glutamate neurotoxicity in hypoxicischemic neuronal death. Annu Rev Neurosci 13:171-182. CrossRef Medline

Dávalos A, Castillo J, Serena J, Noya M (1997) Duration of glutamate release after acute ischemic stroke. Stroke 28:708-710. CrossRef Medline

Dawson TM, Steiner JP, Dawson VL, Dinerman JL, Uhl GR, Snyder SH (1993) Immunosuppressant FK506 enhances phosphorylation of nitric oxide synthase and protects against glutamate neurotoxicity. Proc Natl Acad Sci U S A 90:9808-9812. Medline

de Leeuw B, Su M, ter Horst M, Iwata S, Rodijk M, Hoeben RC, Messing A, Smitt PS, Brenner M (2006) Increased glia-specific transgene expression with glial fibrillary acidic protein promoters containing multiple enhancer elements. J Neurosci Res 83:744-753. CrossRef Medline

Denton RM, Randle PJ, Martin BR (1972) Stimulation by calcium ions of pyruvate dehydrogenase phosphate phosphatase. Biochem J 128: 161-163. Medline

Derouiche A, Haseleu J, Korf HW (2015) Fine astrocyte processes contain very small mitochondria: glial oxidative capability may fuel transmitter metabolism. Neurochem Res 40:2402-2413. CrossRef Medline

Dienel GA (2013) Astrocytic energetics during excitatory neurotransmission: what are contributions of glutamate oxidation and glycolysis? Neurochem Int 63:244-258. CrossRef Medline

Dijk SN, Francis PT, Stratmann GC, Bowen DM (1995) NMDA-induced 
glutamate and aspartate release from rat cortical pyramidal neurones: evidence for modulation by a 5-HT1A antagonist. Br J Pharmacol 115: 1169. CrossRef Medline

Ding S (2014) Ca2 + Signaling in astrocytes and its role in ischemic stroke. In: Glutamate and ATP at the interface of metabolism and signaling in the brain (Parpura V, Schousboe A, Verkhratsky A, eds), pp 189-211. Cham, Switzerland: Springer International.

Ding S, Fellin T, Zhu Y, Lee SY, Auberson YP, Meaney DF, Coulter DA, Carmignoto G, Haydon PG (2007) Enhanced astrocytic $\mathrm{Ca}^{2+}$ signals contribute to neuronal excitotoxicity after status epilepticus. J Neurosci 27:10674-10684. CrossRef Medline

Dröse S, Altendorf K (1997) Bafilomycins and concanamycins as inhibitors of V-ATPases and P-ATPases. J Exp Biol 200:1-8. Medline

Dugan LL, Kim-Han J-S (2004) Astrocyte mitochondria in in vitro models of ischemia. J Bioenerg Biomembr 36:317-321. CrossRef Medline

Dunn KM, Hill-Eubanks DC, Liedtke WB, Nelson MT (2013) TRPV4 channels stimulate $\mathrm{Ca} 2+$-induced $\mathrm{Ca} 2+$ release in astrocytic endfeet and amplify neurovascular coupling responses. Proc Natl Acad Sci U S A 110: 6157-6162. CrossRef Medline

Frederick RL, Shaw JM (2007) Moving mitochondria: establishing distribution of an essential organelle. Traffic 8:1668-1675. CrossRef Medline

Fujimoto S, Katsuki H, Kume T, Kaneko S, Akaike A (2004) Mechanisms of oxygen glucose deprivation-induced glutamate release from cerebrocortical slice cultures. Neurosci Res 50:179-187. CrossRef Medline

Furman JL, Norris CM (2014) Calcineurin and glial signaling: neuroinflammation and beyond. J Neuroinflammation 11:158. CrossRef Medline

Garthwaite J (1985) Cellular uptake disguises action of L-glutamate on $\mathrm{N}$-methyl-D-aspartate receptors. With an appendix: diffusion of transported amino acids into brain slices. Br J Pharmacol 85:297-307. CrossRef Medline

Genda EN, Jackson JG, Sheldon AL, Locke SF, Greco TM, O’Donnell JC, Spruce LA, Xiao R, Guo W, Putt M, Seeholzer S, Ischiropoulos H, Robinson MB (2011) Co-compartmentalization of the astroglial glutamate transporter, GLT-1, with glycolytic enzymes and mitochondria. J Neurosci 31:18275-18288. CrossRef Medline

He L, Lemasters JJ (2002) Regulated and unregulated mitochondrial permeability transition pores: a new paradigm of pore structure and function? FEBS Lett 512:1-7. CrossRef Medline

Hines DJ, Haydon PG (2013) Inhibition of a SNARE-sensitive pathway in astrocytes attenuates damage following stroke. J Neurosci 33:4234-4240. CrossRef Medline

Ichas F, Jouaville LS, Mazat JP (1997) Mitochondria are excitable organelles capable of generating and conveying electrical and calcium signals. Cell 89:1145-1153. CrossRef Medline

Ito U, Hakamata Y, Kawakami E, Oyanagi K (2009) Degeneration of astrocytic processes and their mitochondria in cerebral cortical regions peripheral to the cortical infarction: heterogeneity of their disintegration is closely associated with disseminated selective neuronal necrosis and maturation of injury. Stroke 40:2173-2181. CrossRef Medline

Itoh K, Nakamura K, Iijima M, Sesaki H (2013) Mitochondrial dynamics in neurodegeneration. Trends Cell Biol 23:64-71. CrossRef Medline

Iwamoto T, Kita S (2006) YM-244769, a novel Na+/Ca2 + exchange inhibitor that preferentially inhibits NCX3, efficiently protects against hypoxia/ reoxygenation-induced SH-SY5Y neuronal cell damage. Mol Pharmacol 70:2075-2083. CrossRef Medline

Jackson JG, Robinson MB (2015) Reciprocal regulation of mitochondrial dynamics and calcium signaling in astrocyte processes. J Neurosci 35: 15199-15213. CrossRef Medline

Jackson JG, O’Donnell JC, Takano H, Coulter DA, Robinson MB (2014) Neuronal activity and glutamate uptake decrease mitochondrial mobility in astrocytes and position mitochondria near glutamate transporters. J Neurosci 34:1613-1624. CrossRef Medline

Jiang R, Diaz-Castro B, Looger LL, Khakh BS (2016) Dysfunctional calcium and glutamate signaling in striatal astrocytes from Huntington's disease model mice. J Neurosci 36:3453-3470. CrossRef Medline

Kahraman S, Bambrick LL, Fiskum G (2011) Effects of FK506 and cyclosporin A on calcium ionophore-induced mitochondrial depolarization and cytosolic calcium in astrocytes and neurons. J Neurosci Res 89: 1973-1978. CrossRef Medline

Karaca M, Frigerio F, Migrenne S, Martin-Levilain J, Skytt DM, Pajecka K, Martin-del-Rio R, Gruetter R, Tamarit-Rodriguez J, Waagepetersen HS, Magnan C, Maechler P (2015) GDH-dependent glutamate oxidation in the brain dictates peripheral energy substrate distribution. Cell Rep 13: 365-375. CrossRef Medline

Kim JS, Wang JH, Lemasters JJ (2012) Mitochondrial permeability transition in rat hepatocytes after anoxia/reoxygenation: role of $\mathrm{Ca} 2+-$ dependent mitochondrial formation of reactive oxygen species. Am J Physiol Gastrointest Liver Physiol 302:G723-G731. CrossRef Medline

Lavialle M, Aumann G, Anlauf E, Prols F, Arpin M, Derouiche A (2011) Structural plasticity of perisynaptic astrocyte processes involves ezrin and metabotropic glutamate receptors. Proc Natl Acad Sci USA 108:12915-12919.

Lee IH, Cao L, Mostoslavsky R, Lombard DB, Liu J, Bruns NE, Tsokos M, Alt FW, Finkel T (2008) A role for the NAD-dependent deacetylase Sirt1 in the regulation of autophagy. Proc Natl Acad Sci U S A 105:3374-3379.

Lei Y, Garrahan N, Hermann B, Becker DL, Hernandez MR, Boulton ME, Morgan JE (2008) Quantification of retinal transneuronal degeneration in human glaucoma: a novel multiphoton-DAPI approach. Invest Ophthalmol Vis Sci 49:1940-1945.

Lemasters JJ (2005) Selective mitochondrial autophagy, or mitophagy, as a targeted defense against oxidative stress, mitochondrial dysfunction, and aging. Rejuvenation Res 8:3-5. CrossRef Medline

Lemasters JJ (2014) Variants of mitochondrial autophagy: Types 1 and 2 mitophagy and micromitophagy (Type 3). Redox Biol 2:749-754. CrossRef Medline

Li PA, Kristián T, He QP, Siesjö BK (2000) Cyclosporin A enhances survival, ameliorates brain damage, and prevents secondary mitochondrial dysfunction after a 30-minute period of transient cerebral ischemia. Exp Neurol 165:153-163. CrossRef Medline

Liebeskind DS, Kasner SE (2001) Neuroprotection for ischaemic stroke: an unattainable goal? CNS Drugs 15:165-174. CrossRef Medline

Lipton P (1999) Ischemic cell death in brain neurons. Physiol Rev 79: 1431-1568. Medline

Lovatt D, Sonnewald U, Waagepetersen HS, Schousboe A, He W, Lin JH, Han X, Takano T, Wang S, Sim FJ, Goldman SA, Nedergaard M (2007) The transcriptome and metabolic gene signature of protoplasmic astrocytes in the adult murine cortex. J Neurosci 27:12255-12266. CrossRef Medline

Maday S, Wallace KE, Holzbaur EL (2012) Autophagosomes initiate distally and mature during transport toward the cell soma in primary neurons. J Cell Biol 196:407-417. CrossRef Medline

Magi S, Arcangeli S, Castaldo P, Nasti AA, Berrino L, Piegari E, Bernardini R, Amoroso S, Lariccia V (2013) Glutamate-induced ATP synthesis: relationship between plasma membrane $\mathrm{Na}+/ \mathrm{Ca} 2+$ exchanger and excitatory amino acid transporters in brain and heart cell models. Mol Pharmacol 84:603-614. CrossRef Medline

Matsuda T, Arakawa N, Takuma K, Kishida Y, Kawasaki Y, Sakaue M, Takahashi K, Takahashi T, Suzuki T, Ota T, Hamano-Takahashi A, Onishi M, Tanaka Y, Kameo K, Baba A (2001) SEA0400, a novel and selective inhibitor of the $\mathrm{Na}+-\mathrm{Ca} 2+$ exchanger, attenuates reperfusion injury in the in vitro and in vivo cerebral ischemic models. J Pharmacol Exp Ther 298:249-256. Medline

Mayer ML, Westbrook GL (1987) The physiology of excitatory amino acids in the vertebrate central nervous system. Prog Neurobiol 28:197-276. CrossRef Medline

McKenna MC (2013) Glutamate pays its own way in astrocytes. Front Endocrinol (Lausanne) 4:191. CrossRef Medline

Motori E, Puyal J, Toni N, Ghanem A, Angeloni C, Malaguti M, Cantelli-Forti G, Berninger B, Conzelmann KK, Götz M, Winklhofer KF, Hrelia S, Bergami M (2013) Inflammation-induced alteration of astrocyte mitochondrial dynamics requires autophagy for mitochondrial network maintenance. Cell Metab 18:844-859. CrossRef Medline

Muir KW (2006) Glutamate-based therapeutic approaches: clinical trials with NMDA antagonists. Curr Opin Pharmacol 6:53-60. CrossRef Medline

Nakai A, Kuroda S, Kristián T, Siesjö BK (1997) The immunosuppressant drug FK506 ameliorates secondary mitochondrial dysfunction following transient focal cerebral ischemia in the rat. Neurobiol Dis 4:288-300. CrossRef Medline

Nichols RA, Suplick GR, Brown JM (1994) Calcineurin-mediated protein dephosphorylation in brain nerve terminals regulates the release of glutamate. J Biol Chem 269:23817-23823. Medline

Noraberg J, Poulsen FR, Blaabjerg M, Kristensen BW, Bonde C, Montero M, Meyer M, Gramsbergen JB, Zimmer J (2005) Organotypic hippocampal slice cultures for studies of brain damage, neuroprotection and neurore- 
pair. Curr Drug Targets CNS Neurol Disord 4:435-452. CrossRef Medline

Oliveira JM, Gonçalves J (2008) In situ mitochondrial Ca2+ buffering differences of intact neurons and astrocytes from cortex and striatum. J Biol Chem 284:5010-5020. Medline

Otsu Y, Couchman K, Lyons DG, Collot M, Agarwal A, Mallet JM, Pfrieger FW, Bergles DE, Charpak S (2015) Calcium dynamics in astrocyte processes during neurovascular coupling. Nat Neurosci 18:210-218. CrossRef Medline

Ouyang YB, Voloboueva LA, Xu LJ, Giffard RG (2007) Selective dysfunction of hippocampal CA1 astrocytes contributes to delayed neuronal damage after transient forebrain ischemia. J Neurosci 27:4253-4260. CrossRef Medline

Ouyang YB, Xu LJ, Emery JF, Lee AS, Giffard RG (2011) Overexpressing GRP78 influences $\mathrm{Ca} 2+$ handling and function of mitochondria in astrocytes after ischemia-like stress. Mitochondrion 11:279-286. CrossRef Medline

Ouyang YB, Lu Y, Yue S, Giffard RG (2012) miR-181 targets multiple Bcl-2 family members and influences apoptosis and mitochondrial function in astrocytes. Mitochondrion 12:213-219. CrossRef Medline

Ouyang YB, Xu L, Liu S, Giffard RG (2014) Role of astrocytes in delayed neuronal death: GLT-1 and its novel regulation by microRNAs. In: Glutamate and ATP at the interface of metabolism and signaling in the brain (Parpura V, Schousboe A, Verkhratsky A, eds), pp 171-188. Cham, Switzerland: Springer International.

Parnis J, Montana V, Delgado-Martinez I, Matyash V, Parpura V, Kettenmann H, Sekler I, Nolte C (2013) Mitochondrial exchanger NCLX plays a major role in the intracellular $\mathrm{Ca}^{2+}$ signaling, gliotransmission, and proliferation of astrocytes. J Neurosci 33:7206-7219. CrossRef Medline

Parpura V, Heneka MT, Montana V, Oliet SH, Schousboe A, Haydon PG, Stout RF Jr, Spray DC, Reichenbach A, Pannicke T, Pekny M, Pekna M, Zorec R, Verkhratsky A (2012) Glial cells in (patho)physiology. J Neurochem 121:4-27. CrossRef Medline

Pringle AK, Benham CD, Sim L, Kennedy J, Iannotti F, Sundstrom LE (1996) Selective N-type calcium channel antagonist omega conotoxin MVIIA is neuroprotective against hypoxic neurodegeneration in organotypic hippocampal-slice cultures. Stroke 27:2124-2130. CrossRef Medline

Rininger A, Wayland A, Prifti V, Halterman MW (2012) Assessment of CA1 injury after global ischemia using supervised 2D analyses of nuclear pyknosis. J Neurosci Methods 207:181-188. CrossRef Medline

Rizzuto R, Brini M, Pozzan T (1993) Intracellular targeting of the photoprotein aequorin: a new approach for measuring, in living cells, $\mathrm{Ca}(2+)$ concentrations in defined cellular compartments. Cytotechnology 11: S44-S46. CrossRef Medline

Rizzuto R, Brini M, Pizzo P, Murgia M, Pozzan T (1995) Chimeric green fluorescent protein as a tool for visualizing subcellular organelles in living cells. Curr Biol CB 5:635-642. CrossRef Medline

Rizzuto R, De Stefani D, Raffaello A, Mammucari C (2012) Mitochondria as sensors and regulators of calcium signalling. Nat Rev Mol Cell Biol 13: 566-578. CrossRef Medline

Robinson MB, Jackson JG (2016) Astroglial glutamate transporters coordinate excitatory signaling and brain energetics. Neurochem Int pii:S01970186(16)30040-7. CrossRef Medline

Rodriguez-Enriquez S, He L, Lemasters JJ (2004) Role of mitochondrial permeability transition pores in mitochondrial autophagy. Int J Biochem Cell Biol 36:2463-2472. CrossRef Medline

Rojas H, Colina C, Ramos M, Benaim G, Jaffe E, Caputo C, Di Polo R (2013) Sodium-calcium exchanger modulates the L-glutamate $\mathrm{Ca}(\mathrm{i})(2+)$ signalling in type-1 cerebellar astrocytes. Adv Exp Med Biol 961:267-274. CrossRef Medline

Rossi DJ, Brady JD, Mohr C (2007) Astrocyte metabolism and signaling during brain ischemia. Nat Neurosci 10:1377-1386. Medline

Salinet AS, Robinson TG, Panerai RB (2015) Effects of cerebral ischemia on human neurovascular coupling, $\mathrm{CO}_{2}$ reactivity, and dynamic cerebral autoregulation. J Appl Physiol 118:170-177. CrossRef Medline

Sasaki T, Ishikawa T, Abe R, Nakayama R, Asada A, Matsuki N, Ikegaya Y (2014) Astrocyte calcium signalling orchestrates neuronal synchronization in organotypic hippocampal slices. J Physiol 592:2771-2783. CrossRef Medline

Schindelin J, Arganda-Carreras I, Frise E, Kaynig V, Longair M, Pietzsch T, Preibisch S, Rueden C, Saalfeld S, Schmid B, Tinevez JY, White DJ, Hartenstein V, Eliceiri K, Tomancak P, Cardona A (2012) Fiji: an open- source platform for biological-image analysis. Nat Methods 9:676-682. CrossRef Medline

Schröder UH, Breder J, Sabelhaus CF, Reymann KG (1999) The novel Na+/Ca2+ exchange inhibitor KB-R7943 protects CA1 neurons in rat hippocampal slices against hypoxic/hypoglycemic injury. Neuropharmacology 38:319-321. CrossRef Medline

Schwarz TL (2013) Mitochondrial trafficking in neurons. Cold Spring Harb Perspect Biol 5:pii:a011304. CrossRef Medline

Sheng ZH, Cai Q (2012) Mitochondrial transport in neurons: impact on synaptic homeostasis and neurodegeneration. Nat Rev Neurosci 13: 77-93. CrossRef Medline

Shimamoto K, Sakai R, Takaoka K, Yumoto N, Nakajima T, Amara SG, Shigeri Y (2004) Characterization of novel L-threo-beta-benzyloxyaspartate derivatives, potent blockers of the glutamate transporters. Mol Pharmacol 65:1008-1015. CrossRef Medline

Starkov AA, Fiskum G, Chinopoulos C, Lorenzo BJ, Browne SE, Patel MS, Beal MF (2004) Mitochondrial $\alpha$-ketoglutarate dehydrogenase complex generates reactive oxygen species. J Neurosci 24:7779-7788. Medline

Stephen TL, Higgs NF, Sheehan DF, Al Awabdh S, López-Doménech G, Arancibia-Carcamo IL, Kittler JT (2015) Mirol regulates activitydriven positioning of mitochondria within astrocytic processes apposed to synapses to regulate intracellular calcium signaling. J Neurosci 35 : 15996-16011. CrossRef Medline

Stoppini L, Buchs PA, Muller D (1991) A simple method for organotypic cultures of nervous tissue. J Neurosci Methods 37:173-182. Medline

Strijbos PJ, Leach MJ, Garthwaite J (1996) Vicious cycle involving $\mathrm{Na}+$ channels, glutamate release, and NMDA receptors mediates delayed neurodegeneration through nitric oxide formation. J Neurosci 16: 5004-5013. Medline

Takano T, Tian GF, Peng W, Lou N, Libionka W, Han X, Nedergaard M (2006) Astrocyte-mediated control of cerebral blood flow. Nat Neurosci 9:260-267. Medline

Takemiya T, Yamagata K (2013) Intercellular signaling pathway among endothelia, astrocytes and neurons in excitatory neuronal damage. Int J Mol Sci 14:8345-8357. CrossRef Medline

Tanida I, Ueno T, Kominami E (2008) LC3 and autophagy. In: Autophagosome and phagosome (Deretic V, ed), pp 77-88. Totowa, NJ: Humana.

Tretter L, Adam-Vizi V (2004) Generation of reactive oxygen species in the reaction catalyzed by alpha-ketoglutarate dehydrogenase. J Neurosci 24 : 7771-7778. CrossRef Medline

Trumbeckaite S, Gizatullina Z, Arandarcikaite O, Röhnert P, Vielhaber S, Malesevic M, Fischer G, Seppet E, Striggow F, Gellerich FN (2013) Oxygen glucose deprivation causes mitochondrial dysfunction in cultivated rat hippocampal slices: protective effects of CsA, its immunosuppressive congener [D-Ser] $8 \mathrm{CsA}$, the novel non-immunosuppressive cyclosporin derivative Cs9, and the NMDA receptor antagonist MK 801. Mitochondrion 13:539-547. CrossRef Medline

Tsien RY (1998) The green fluorescent protein. Annu Rev Biochem 67: 509-544. CrossRef Medline

Uchino H, Elmér E, Uchino K, Li PA, He QP, Smith ML, Siesjö BK (1998) Amelioration by cyclosporin A of brain damage in transient forebrain ischemia in the rat. Brain Res 812:216-226. CrossRef Medline

Ugbode CI, Hirst WD, Rattray M (2014) Neuronal influences are necessary to produce mitochondrial co-localization with glutamate transporters in astrocytes. J Neurochem 130:668-677. CrossRef Medline

Valentino K, Newcomb R, Gadbois T, Singh T, Bowersox S, Bitner S, Justice A, Yamashiro D, Hoffman BB, Ciaranello R (1993) A selective N-type calcium channel antagonist protects against neuronal loss after global cerebral ischemia. Proc Natl Acad Sci U S A 90:7894-7897. CrossRef Medline

Vornov JJ, Tasker RC, Coyle JT (1991) Direct observation of the agonistspecific regional vulnerability to glutamate, NMDA, and kainate neurotoxicity in organotypic hippocampal cultures. Exp Neurol 114:11-22. CrossRef Medline

Wang GJ, Jackson JG, Thayer SA (2003) Altered distribution of mitochondria impairs calcium homeostasis in rat hippocampal neurons in culture. J Neurochem 87:85-94. CrossRef Medline

Whitelaw BS, Robinson MB (2013) Inhibitors of glutamate dehydrogenase block sodium-dependent glutamate uptake in rat brain membranes. Front Endocrinol (Lausanne) 4:123. CrossRef Medline

Woeffler-Maucler C, Beghin A, Ressnikoff D, Bezin L, Marinesco S (2014) Automated immunohistochemical method to quantify neuronal density 
in brain sections: application to neuronal loss after status epilepticus. J Neurosci Methods 225:32-41. CrossRef Medline

Wong YC, Holzbaur EL (2014) Optineurin is an autophagy receptor for damaged mitochondria in parkin-mediated mitophagy that is disrupted by an ALS-linked mutation. Proc Natl Acad Sci U S A 111:E4439-E4448. CrossRef Medline

Yang Y, Li Q, Miyashita H, Yang T, Shuaib A (2001) Different dynamic patterns of extracellular glutamate release in rat hippocampus after permanent or 30-min transient cerebral ischemia and histological correlation. Neuropathology 21:181-187. CrossRef Medline

Yokoyama T, Tanoue T, Hasegawa E, Ikeda Y, Ohta S, Omi A, Kudo Y, Uchino H (2012) Evaluation of the protective effects of cyclosporin A and FK506 on abnormal cytosolic and mitochondrial $\mathrm{Ca}^{2+}$ dynamics during ischemia and exposure to high glutamate concentration in mouse brain slice preparations. J Pharmacol Sci 120:228-240. CrossRef Medline

Zaganas I, Waagepetersen HS, Georgopoulos P, Sonnewald U, Plaitakis A,
Schousboe A (2001) Differential expression of glutamate dehydrogenase in cultured neurons and astrocytes from mouse cerebellum and cerebral cortex. J Neurosci Res 66:909-913. CrossRef Medline

Zhang Y, Chen K, Sloan SA, Bennett ML, Scholze AR, O'Keeffe S, Phatnani HP, Guarnieri P, Caneda C, Ruderisch N, Deng S, Liddelow SA, Zhang C, Daneman R, Maniatis T, Barres BA, Wu JQ (2014) An RNA-sequencing transcriptome and splicing database of glia, neurons, and vascular cells of the cerebral cortex. J Neurosci 34:11929-11947. CrossRef Medline

Zheng W, Talley Watts L, Holstein DM, Wewer J, Lechleiter JD (2013) P2Y1R-initiated, IP3R-dependent stimulation of astrocyte mitochondrial metabolism reduces and partially reverses ischemic neuronal damage in mouse. J Cereb Blood Flow Metab 33:600-611. CrossRef Medline

Zhou X, Hollern D, Liao J, Andrechek E, Wang H (2013) NMDA receptormediated excitotoxicity depends on the coactivation of synaptic and extrasynaptic receptors. Cell Death Dis 4:e560. CrossRef Medline 